\title{
Development of Topography within Song Control Circuitry of Zebra Finches during the Sensitive Period for Song Learning
}

\author{
Soumya lyengar, Sandya S. Viswanathan, and Sarah W. Bottjer \\ Department of Biology, University of Southern California, Los Angeles, California 90089-2520
}

Refinement of topographic maps during sensitive periods of development is a characteristic feature of diverse sensory and motor circuits in the nervous system. Within the neural system that controls vocal learning and behavior in zebra finches, axonal connections of the cortical nucleus IMAN demonstrate striking functional and morphological changes during vocal development in juvenile males. These circuits are uniquely important for song production during the sensitive period for vocal learning, and the overall size of these brain regions and their patterns of axonal connectivity undergo dramatic growth and regression during this time. Axonal connections to and from IMAN are topographically organized in adult males that have already learned song. We wondered whether the large-scale changes seen in IMAN circuitry during the time that vocal behavior is being learned and refined could be accompanied by the emergence of topographic mapping. However, results presented herein demonstrate that most of these song-control circuits show the same broad patterns of axonal connectivity between subregions of individual nuclei at the onset of song

Two fundamental questions of developmental neurobiology pertain to how the brain gets wired up correctly and how the specificity of neural connections relates to the emergence of learned behaviors during sensitive periods of development. Whereas some neural circuits demonstrate remarkably precise patterns of connectivity very early in postnatal development (for example, the somatosensory system in rats) (Catalano et al., 1991; Agmon et al., 1993, 1995), other circuits lack topographic specificity in young animals and are sculpted during specific sensitive periods of development to give rise to topographically organized circuits in adults (such as the retinocollicular system in rats) (O'Leary et al., 1986; Simon and O'Leary, 1992). Thus, different developmental mechanisms underlie the emergence of topographic organization within different neural circuits.

The neural substrate that controls vocal behavior in songbirds has provided a model system for studying the development of neural circuitry involved in learning a complex behavior. Neural pathways that control vocal behavior in male zebra finches show striking functional and morphological changes during vocal development. One developmentally regulated vocal-control circuit consists of a striatothalamocortical pathway: Area X (within avian striatum) projects to the thalamic nucleus medial dorsolat-

Received Jan. 19, 1999; revised April 28, 1999; accepted May 4, 1999.

This research was supported by National Institutes of Health Grant DC00190. We thank Linh Ho for excellent technical assistance and Frank Johnson for assistance with analysis of topography in adult birds.

Correspondence should be addressed to Soumya Iyengar, Department of Biology, HNB 218, University of Southern California, Los Angeles, CA 90089-2520.

Copyright (C) 1999 Society for Neuroscience 0270-6474/99/196037-21\$05.00/0 learning as seen in adult birds. Thus, coarse topographic organization is not dependent on the types of experience that are crucial for vocal learning. Furthermore, this maintenance of topographic organization throughout the period of song learning is clearly not achieved by maintenance of static axonal arbors. In fact, because the volumes of song-control nuclei are growing (or regressing), topography must be maintained by active remodeling of axonal arbors to adapt to the changes in overall size of postsynaptic targets. A salient exception to this pattern of conserved topography is the projection from IMAN to the motor cortical region RA: this pathway is diffusely organized at the onset of song learning but undergoes substantial refinement during early stages of song learning, suggesting that remodeling of axonal connections within this projection during the period of vocal learning may signify the production of increasingly refined vocal utterances.

Key words: topography; sensitive periods; zebra finch; songbird; vocal learning; axon arbors; basal ganglia eral nucleus of the thalamus (DLM); DLM projects to the cortical nucleus, lateral magnocellular nucleus of the anterior neostriatum (IMAN), which projects to the motor cortical regions robust nucleus of the archistriatum (RA) and dorsal archistriatum (Ad) (Bottjer et al., 1989; Johnson et al., 1995) (Fig. 1). Lesions within this pathway disrupt song learning in juvenile birds $(20-55 \mathrm{~d})$ but do not affect already learned song in adults ( $\geq 90 \mathrm{~d}$ ) (Bottjer et al., 1984; Sohrabji et al., 1990; Scharff and Nottebohm, 1991). During the sensitive period for song learning, the thalamocortical projection from DLM to IMAN undergoes substantive growth, followed by an equally dramatic regression between $35 \mathrm{~d}$ and adulthood (Johnson and Bottjer, 1992; cf. Bottjer, 1997; Bottjer and Arnold, 1997; Nordeen and Nordeen, 1997). Because the total number of DLM neurons remains constant throughout vocal learning, changes in the terminal field of DLM neurons within IMAN presumably occur at the level of individual DLM axon arbors (Iyengar and Bottjer, 1998). Synaptic rearrangements must also occur within the projection from IMAN to RA, because the number of synapses made by $1 \mathrm{MAN}$ axons within RA decreases substantially over the course of vocal learning, whereas the absolute number of IMAN projection neurons remains constant during this period (Herrmann and Arnold, 1991; Nordeen et al., 1992).

The $\mathrm{DLM} \rightarrow \mathrm{IMAN} \rightarrow \mathrm{RA} /$ Ad pathway actually consists of two independent circuits that traverse the forebrain in parallel (Johnson et al., 1995) (Fig. 1). Projections within both of these pathways are topographically organized in adult birds. However, the enormous morphological changes taking place in the volume 


\section{The Song Control System}

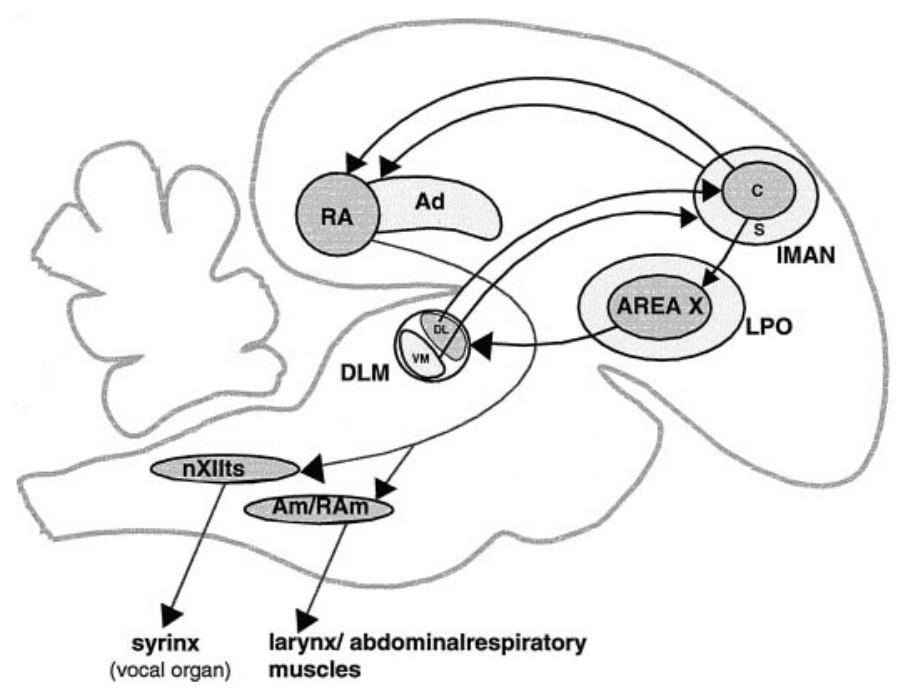

Figure 1. Schematic sagittal view of the song control system of an adult male zebra finch. Area X (a nucleus of the avian basal ganglia) projects to the thalamic nucleus DLM. The dorsolateral $(D L)$ subregion of DLM projects to a central core of magnocellular neurons within the cortical nucleus IMAN, whereas the ventromedial $(V M)$ part of DLM projects solely to a shell surrounding $1 \mathrm{MAN}_{\text {core, }}$, which consists primarily of parvicellular neurons (Johnson and Bottjer, 1992). In addition to receiving different afferents, the core and shell subregions of IMAN project to different targets: whereas $1 \mathrm{MAN}_{\text {core }}$ projects to RA and Area X, $1 \mathrm{MAN}$ shell projects to a region adjacent to RA called Ad (Bottjer et al., 1989; Johnson et al., 1995; Vates and Nottebohm, 1995). X, Area X of the avian striatum; $D L M$, medial portion of the dorsolateral region of the anterior thalamus; $I M A N$, lateral magnocellular nucleus of the anterior neostriatum; $R A$, robust nucleus of the archistriatum; $A d$, dorsal archistriatum; $n X I I t s$, tracheosyringeal part of the hypoglossal nucleus; $n A m$, nucleus ambiguus; $n R A m$, nucleus retroambigualis; $c$, core; $s$, shell.

of individual song-control brain regions and their overall axonal projections suggest that dynamic rearrangements of topographic patterns within song control circuitry may occur during vocal learning (Bottjer, 1997). We tested this idea by comparing broad patterns of axonal connectivity within the $\mathrm{DLM} \rightarrow \mathrm{IMAN} \rightarrow \mathrm{RA} / \mathrm{Ad}$ circuits of male zebra finches during early stages of song learning with those of adults. Our findings reveal that the coarse topographic organization of most axonal projections to and from IMAN is indistinguishable in juvenile and adult birds, despite the striking growth and regression seen in these brain nuclei during song learning. These results suggest that broad patterns of topography within these circuits are already established by the onset of song learning and do not depend on experiences associated with vocal learning. Furthermore, these topographic patterns must be maintained in the face of largescale changes in song-control circuits by active remodeling of axonal arbors. A major exception was the $\mathrm{IMAN}_{\text {core }} \rightarrow \mathrm{RA}$ circuit in $20 \mathrm{~d}$ birds, in which overall patterns of connectivity were poorly refined as compared with those in older birds. Interestingly, the adult pattern emerged within this circuit between 20 and $35 \mathrm{~d}$ of age, suggesting that refinement of topography within this circuit may accompany learning about the acoustic features of song or their motor representation (Marler, 1991; Zann, 1996).

\section{MATERIALS AND METHODS}

All birds used in this study were bred in our aviaries and received normal exposure to song before surgeries. The surgical procedures used in this study were in accordance with National Institutes of Health guidelines and the Animal Care and Use Committee at the University of Southern California.

Dye injections. Juvenile male zebra finches (18-20 d after hatching, $n=$ 14 ; 33-37 d after hatching, $n=9)$ and adult male zebra finches $(\geq 90 \mathrm{~d}$, $n=18$ ) (Table 1) were anesthetized with $0.04-0.06 \mathrm{ml}$ of the barbiturate anesthetic Equithesin and placed in a stereotaxic apparatus. A midline incision was made in the scalp, and small parts of the skull over IMAN were removed on both sides of the brain using predetermined coordinates. Micropipettes $(25-30 \mu \mathrm{m}$, outer diameter) were filled with the fluorescent tracers rhodamine dextran amine (RDA) (10\% solution in $0.02 \mathrm{M}$ PBS) or fluorescein dextran amine (FDA) (20\% solution in 0.02 M PBS) (Molecular Probes, Eugene, OR) and lowered into the brain. A Picospritzer was used to make small injections of different dyes into $1 \mathrm{MAN}_{\text {core }}$ and $1 \mathrm{MAN}_{\text {shell }}$ on both sides of the brain.

For each dye injection, two $10 \mathrm{msec}$ air pulses were made at $35 \mathrm{psi}$, yielding a volume of $\sim 2-5 \mathrm{nl}$ at the injection site. Clogging of the pipette tips led to variations in the size of injections in IMAN within different birds. Dye injections targeted to both core and shell regions of IMAN in individual birds were counterbalanced such that if RDA and FDA were injected into $1 \mathrm{MAN} \mathrm{N}_{\text {core }}$ and $1 \mathrm{MAN}_{\text {shell }}$, respectively, on one side of the brain, then FDA was injected into $1 \mathrm{MAN}$ core and RDA into $1 \mathrm{MAN}_{\text {shell }}$ on the other side. In addition, some birds (18-20 d birds, $n=5 ; 33-37 \mathrm{~d}$ birds, $n=1$; adult birds, $n=9$ ) received injections of RDA alone into right and left $1 \mathrm{MAN} \mathrm{N}_{\text {core }}$. After surgery, juvenile zebra finches were returned to their parents in group breeding aviaries, whereas adult birds were placed in separate cages. A survival time of $3 \mathrm{~d}$ after surgery was allowed for axonal transport of the dyes, after which birds were deeply anesthetized and perfused transcardially with $0.7 \%$ saline followed by $10 \%$ buffered formalin. Brains were removed and post-fixed in $10 \%$ buffered formalin for 5-7 d and then cryoprotected in $25 \%$ sucrose overnight. A cryostat $\left(-21^{\circ} \mathrm{C}\right)$ was used to section brains coronally at a thickness of $50 \mu \mathrm{m}$, and two alternate series of sections were collected on slides coated with gelatin. One series was coverslipped with buffered glycerol immediately after sectioning and stored at $4^{\circ} \mathrm{C}$. The second series was allowed to dry overnight, Nissl stained with thionin, and coverslipped with Permount.

Analysis. In all birds, the first series of slides was observed under an epifluorescence microscope using rhodamine filters for RDA and fluorescein filters for FDA. Injection sites within IMAN core and shell and the resulting retrograde and anterograde label in different regions of the brain were photographed. Retrograde and anterograde label resulting from dye injections that included parts of both core and shell regions of IMAN were comparable to patterns of label produced by injections that included only $1 \mathrm{MAN}_{\text {core }}$ or $1 \mathrm{MAN}_{\text {shell. }}$. Therefore, these injections were included with injections that were restricted to only $1 \mathrm{MAN}_{\text {core }}$ or $1 \mathrm{MAN}$ shell for analysis. The thionin-stained series was used to trace the Nissldefined borders of IMAN using a camera lucida. To confirm the exact size and position of the injection sites within IMAN, injection sites were viewed in the fluorescent series of slides and traced onto these Nissldefined outlines. In the same manner, the Nissl-defined borders of DLM were traced using a camera lucida, and retrogradely labeled neurons in DLM produced by injections of RDA and FDA into ipsilateral IMAN were then traced onto these outlines to determine whether the distribution of labeled cells was different in juveniles compared with adult birds.

Although both RDA and FDA injections within IMAN produced retrograde label of comparable brightness, only RDA produced intense anterograde labeling of axons and terminal arborizations. Anterograde fluorescent label produced by injections of FDA into IMAN was very weak and difficult to photograph. Therefore, only patterns of anterograde label produced by RDA injections into IMAN core and shell were photographed and compared across birds of different ages.

Qualitative inspection of anterograde label was sufficient for making comparisons among brains of different ages for all circuits except the $1 \mathrm{MAN}_{\text {core }} \rightarrow \mathrm{RA}$ projection. Surprisingly, initial inspection of the $\mathrm{IMAN}_{\text {core }} \rightarrow \mathrm{RA}$ pathway revealed robust age differences, whereas the organization of the collateral projection from $1 \mathrm{MAN}_{\text {core }}$ neurons onto Area $\mathrm{X}$ appeared to be comparable at different ages. We decided to confirm these observations by quantifying the volume of anterogradely labeled arbors within both RA and Area X produced by injections of RDA into $1 M A N_{\text {core }}$. We outlined the anterograde label within RA and Area $\mathrm{X}$ of birds in which both the injection site in $\mathrm{IMAN}_{\text {core }}$ and the 
Table 1. Summary of RDA and FDA injections into IMAN

\begin{tabular}{|c|c|c|c|c|c|c|c|c|c|c|c|c|c|}
\hline \multirow[b]{2}{*}{ Age } & \multirow{2}{*}{$\begin{array}{l}\text { Total \# of } \\
\text { birds }\end{array}$} & \multicolumn{3}{|c|}{ Inj into $1 \mathrm{MAN}_{\text {core }}$} & \multicolumn{3}{|c|}{ Inj into $1 \mathrm{MAN}_{\text {shell }}$} & \multicolumn{3}{|c|}{$\begin{array}{l}{ }^{a} \text { Inj into both IMAN core } \\
\text { and shell }\end{array}$} & \multicolumn{2}{|c|}{$\begin{array}{l}\text { Control inj } \\
\text { (outside IMAN) } \\
\end{array}$} & \multirow{2}{*}{$\begin{array}{l}\text { Total \# } \\
\text { of inj }\end{array}$} \\
\hline & & RDA & FDA & Total & RDA & FDA & Total & RDA & FDA & Total & RDA & FDA & \\
\hline $20 \mathrm{~d}$ & 14 & 10 & 1 & 11 & 7 & 5 & 12 & 10 & 4 & 14 & 0 & 1 & 38 \\
\hline $35 \mathrm{~d}$ & 9 & 3 & 3 & 6 & 2 & 6 & 8 & 5 & 2 & 7 & 3 & 2 & 26 \\
\hline Adult & 18 & 11 & 0 & 11 & 10 & 5 & 15 & 7 & 8 & 15 & 2 & 3 & 47 \\
\hline Total & 41 & & & & & & & & & & & & 111 \\
\hline
\end{tabular}

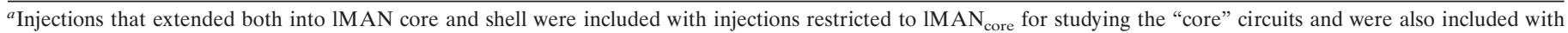
injections within $\mathrm{IMAN}_{\text {shell }}$ for analyzing the "shell" circuits.

Table 2. Quantitative analysis of anterograde label over RA after injections into IMAN $_{\text {core }}$

\begin{tabular}{|c|c|c|c|c|c|c|c|c|c|}
\hline $\begin{array}{l}\text { Age of } \\
\text { birds }\end{array}$ & Bird & $\begin{array}{l}\text { Total number } \\
\text { of injections }\end{array}$ & Location $^{a}$ & $\begin{array}{l}\text { Injection site } \\
\text { in } \mathrm{lMAN}_{\text {core }} \\
\left(\mathrm{mm}^{3}\right)^{b}\end{array}$ & $\begin{array}{l}\text { Volume of } \\
\text { ipsilateral } \\
\text { RA } \\
\left(\mathrm{mm}^{3}\right)\end{array}$ & $\begin{array}{l}\text { Volume of } \\
\text { lMAN }_{\text {core }} \\
\text { arbors in } \\
\text { RA } \\
\left(\mathrm{mm}^{3}\right)\end{array}$ & $\begin{array}{l}\text { (Vol. of arbors)/ } \\
\text { (vol. of RA) }\end{array}$ & $\begin{array}{l}\text { Retrograde } \\
\text { label in } \mathrm{DLM}^{c}\end{array}$ & $\begin{array}{l}\text { Anterograde } \\
\text { label in } X^{c}\end{array}$ \\
\hline \multirow[t]{15}{*}{$20 \mathrm{~d}$} & R524 rt & \multirow[t]{15}{*}{13} & $\mathrm{M}$ & 0.007 & 0.123 & 0.067 & 0.540 & $\mathrm{xx}$ & $\mathrm{xx}$ \\
\hline & R551 lt & & M & 0.008 & 0.144 & 0.066 & 0.460 & $\mathrm{xx}$ & $x-$ \\
\hline & Pu514 rt & & $\mathrm{M}$ & 0.009 & 0.143 & 0.103 & 0.720 & $\mathrm{xxx}$ & $\mathrm{xxx}$ \\
\hline & $\mathrm{R} 551 \mathrm{rt}$ & & M & 0.010 & 0.147 & 0.096 & 0.650 & $\mathrm{xx}$ & $\mathrm{x}$ \\
\hline & Pu514 lt & & $\mathrm{I}+\mathrm{M}$ & 0.011 & 0.153 & 0.110 & 0.720 & $\mathrm{xxx}$ & $\mathrm{xxx}$ \\
\hline & Bk307 & & $\mathrm{L}+\mathrm{I}$ & 0.012 & 0.126 & 0.078 & 0.620 & $\mathrm{x}$ & $\mathrm{x}$ \\
\hline & W453 & & $\mathrm{I}+\mathrm{M}$ & 0.013 & 0.144 & 0.118 & 0.820 & $\mathrm{xxx}$ & $\mathrm{xxx}$ \\
\hline & Bk434 & & M & 0.016 & 0.059 & 0.040 & 0.690 & $\mathrm{xx}$ & $\mathrm{x}$ \\
\hline & R524 lt & & $\mathrm{L}+\mathrm{I}$ & 0.016 & 0.135 & 0.064 & 0.470 & $\mathrm{xx}$ & $\mathrm{xx}$ \\
\hline & $\mathrm{W} 462 \mathrm{rt}$ & & $\mathrm{L}$ & 0.019 & 0.121 & 0.047 & 0.390 & $\mathrm{xx}$ & $\mathrm{xx}$ \\
\hline & W462 lt & & $\mathrm{L}+\mathrm{I}$ & 0.020 & 0.136 & 0.083 & 0.610 & $\mathrm{xx}$ & $\mathrm{xx}$ \\
\hline & Pu511 & & M & 0.021 & 0.121 & 0.119 & 0.980 & $\mathrm{xxx}$ & $\mathrm{xxx}$ \\
\hline & W342 & & I & 0.036 & 0.101 & 0.077 & 0.760 & $\mathrm{xxx}$ & $\mathrm{xxx}$ \\
\hline & Mean & & & 0.015 & 0.127 & 0.082 & 0.648 & & \\
\hline & SD & & & 0.008 & 0.025 & 0.026 & 0.161 & & \\
\hline \multirow[t]{7}{*}{$35 \mathrm{~d}$} & Lb493 lt & \multirow[t]{7}{*}{5} & $\mathrm{~L}$ & 0.008 & 0.318 & 0.100 & 0.330 & $\mathrm{xx}$ & $\mathrm{xx}$ \\
\hline & Dg343 & & M & 0.011 & 0.129 & 0.009 & 0.070 & $\mathrm{x}$ & $\mathrm{x}$ \\
\hline & Lb493 rt & & $\mathrm{L}$ & 0.013 & 0.300 & 0.083 & 0.280 & $\mathrm{xx}$ & $\mathrm{x}$ \\
\hline & Bk404 & & $\mathrm{L}$ & 0.022 & 0.262 & 0.058 & 0.220 & $\mathrm{xx}$ & $\mathrm{xx}$ \\
\hline & Y431 & & $\mathrm{L}$ & 0.058 & 0.246 & 0.047 & 0.190 & $\mathrm{xx}$ & $x-$ \\
\hline & Mean & & & 0.022 & 0.251 & 0.059 & 0.218 & & \\
\hline & SD & & & 0.021 & 0.074 & 0.035 & 0.099 & & \\
\hline \multirow[t]{11}{*}{ Adult } & W391 & \multirow[t]{11}{*}{9} & I & 0.009 & 0.337 & 0.080 & 0.240 & $\mathrm{xx}$ & $\mathrm{xx}$ \\
\hline & W421 & & $\mathrm{I}+\mathrm{M}$ & 0.009 & 0.260 & 0.094 & 0.360 & $\mathrm{xxx}$ & $\mathrm{xxx}$ \\
\hline & Lb994 lt & & $\mathrm{L}$ & 0.009 & 0.220 & 0.082 & 0.370 & $\mathrm{xxx}$ & $\mathrm{xx}$ \\
\hline & Bk389 & & $\mathrm{L}+\mathrm{I}$ & 0.011 & 0.318 & 0.173 & 0.540 & $\mathrm{xx}$ & $\mathrm{xx}$ \\
\hline & Lb994 rt & & $\mathrm{L}+\mathrm{I}$ & 0.011 & 0.210 & 0.061 & 0.290 & $\mathrm{xxx}$ & $\mathrm{xx}$ \\
\hline & Y325 & & $\mathrm{M}$ & 0.013 & 0.202 & 0.073 & 0.360 & $\mathrm{x}$ & $\mathrm{xx}$ \\
\hline & W425 & & $\mathrm{L}$ & 0.015 & 0.347 & 0.106 & 0.310 & $\mathrm{xxx}$ & $\mathrm{xx}$ \\
\hline & Bk311 & & $\mathrm{M}$ & 0.020 & 0.389 & 0.155 & 0.390 & $\mathrm{xx}$ & $\mathrm{xx}$ \\
\hline & Y999 & & M & 0.037 & 0.318 & 0.146 & 0.460 & $\mathrm{xxx}$ & $\mathrm{xxx}$ \\
\hline & Mean & & & 0.015 & 0.289 & 0.108 & 0.369 & & \\
\hline & SD & & & 0.009 & 0.068 & 0.040 & 0.090 & & \\
\hline
\end{tabular}

${ }^{a} \mathrm{~L}$, lateral; I, intermediate; M, medial.

${ }^{b}$ Injection sites in $\mathrm{IMAN}_{\text {core }}$ are given in increasing order of volume.

${ }^{c}$ Retrograde label in $\mathrm{DLM}_{\mathrm{DL}}$ and anterograde label in Area X produced by RDA injections into $\mathrm{IMAN}_{\text {core }}$ were ranked qualitatively.

$\mathrm{x}-$, Sparse label; $\mathrm{x}, \mathrm{xx}, \mathrm{xxx}$, increasing amounts of label.

anterogradely labeled terminal field in RA and Area X were well defined [20 d $(n=13), 35 \mathrm{~d}(n=5)$, and adult $(n=9)$ birds for RA, Table 2, and $20 \mathrm{~d}(n=10)$ and adult birds $(n=8)$ for Area X, Table 3]. An image analysis system was used for capturing images of RA and Area X from both fluorescent and Nissl-stained sections. The area of anterograde label within both these nuclei was outlined on each section in which they appeared using software from Media Cybernetics (Image Pro Plus). The total volume of anterograde label within RA and Area X was estimated by adding these areas and multiplying by the sampling interval $(100 \mu \mathrm{m})$. The same method was used to reconstruct the volume of the RDA 


\begin{tabular}{|c|c|c|c|c|c|c|c|}
\hline $\begin{array}{l}\text { Age of } \\
\text { birds }\end{array}$ & Bird & $\begin{array}{l}\text { Total number } \\
\text { of injections }\end{array}$ & Location & $\begin{array}{l}\text { Injection site } \\
\text { in } \mathrm{IMAN}_{\text {core }} \\
\left(\mathrm{mm}^{3}\right)\end{array}$ & $\begin{array}{l}\text { Volume of } \\
\text { ipsilateral X } \\
\left(\mathrm{mm}^{3}\right)\end{array}$ & $\begin{array}{l}\text { Volume of IMAN- } \\
\text { core arbors in } \mathrm{X} \\
\left(\mathrm{mm}^{3}\right)\end{array}$ & $\begin{array}{l}\text { (Vol. of } \\
\text { arbors)/ } \\
\text { (vol. of X) }\end{array}$ \\
\hline \multirow[t]{12}{*}{$20 \mathrm{~d}$} & $\mathrm{R} 524 \mathrm{rt}$ & 10 & $\mathrm{M}$ & 0.007 & 0.76 & 0.07 & 0.09 \\
\hline & Pu514 rt & & M & 0.008 & 0.83 & 0.15 & 0.18 \\
\hline & R551 rt & & $\mathrm{M}$ & 0.010 & 1.00 & 0.03 & 0.03 \\
\hline & Pu514 lt & & $\mathrm{I}+\mathrm{M}$ & 0.011 & 1.03 & 0.14 & 0.14 \\
\hline & W453 & & $\mathrm{I}+\mathrm{M}$ & 0.013 & 0.92 & 0.27 & 0.29 \\
\hline & R524 lt & & $\mathrm{L}+\mathrm{I}$ & 0.016 & 0.86 & 0.06 & 0.07 \\
\hline & $\mathrm{W} 462 \mathrm{rt}$ & & $\mathrm{L}$ & 0.019 & 1.06 & 0.23 & 0.22 \\
\hline & W462 lt & & $\mathrm{L}+\mathrm{I}$ & 0.020 & 1.13 & 0.27 & 0.24 \\
\hline & Pu511 & & M & 0.021 & 0.76 & 0.24 & 0.32 \\
\hline & W342 & & I & 0.036 & 0.91 & 0.36 & 0.40 \\
\hline & Mean & & & 0.016 & 0.93 & 0.18 & 0.20 \\
\hline & SD & & & 0.008 & 0.13 & 0.11 & 0.12 \\
\hline \multirow[t]{10}{*}{ Adult } & W391 & 8 & I & 0.009 & 1.50 & 0.07 & 0.05 \\
\hline & W421 & & $\mathrm{I}+\mathrm{M}$ & 0.009 & 1.80 & 0.11 & 0.06 \\
\hline & Lb994 lt & & $\mathrm{L}$ & 0.009 & 2.00 & 0.19 & 0.10 \\
\hline & Bk389 & & $\mathrm{L}+\mathrm{I}$ & 0.011 & 1.30 & 0.20 & 0.15 \\
\hline & Y325 & & M & 0.013 & 2.20 & 0.24 & 0.11 \\
\hline & W425 & & $\mathrm{L}$ & 0.015 & 1.60 & 0.12 & 0.08 \\
\hline & Bk311 & & M & 0.020 & 1.90 & 0.45 & 0.24 \\
\hline & Y999 & & M & 0.037 & 1.60 & 0.85 & 0.53 \\
\hline & Mean & & & 0.015 & 1.74 & 0.28 & 0.16 \\
\hline & SD & & & 0.010 & 0.29 & 0.26 & 0.16 \\
\hline
\end{tabular}

injection site in fluorescent sections of ipsilateral $1 \mathrm{MAN}_{\text {core }}$. The total volume of RA and Area X was reconstructed from Nissl-stained sections (comparison of the cross-sectional area of these nuclei in Nissl-stained and fluorescent sections showed that these areas were comparable, i.e., there was no differential shrinkage of the tissue). Therefore, the borders of RA and Area X were outlined in Nissl-stained sections, and the resultant areas were added and multiplied by the sampling interval to estimate the total volume of these nuclei. The percentage of each nucleus occupied by anterogradely labeled axons from $1 \mathrm{MAN}_{\text {core }}$ was then calculated by dividing the volume of labeled axonal arbors within each nucleus in each bird by the total volume of the respective nucleus (RA or Area $\mathrm{X}$ ) in that bird (Tables 2, 3).

Despite using a fixed volume of RDA for our injections, the volume of injection sites in $1 \mathrm{MAN}$ was variable in different birds, although the average size of injection sites was roughly comparable between age groups (Tables 2,3). There was not a systematic relationship between the size of the injection and the size of the terminal field within RA (or Area $\mathrm{X}$ ), as is typical of any tract tracing study. The absence of a tight correspondence between the size of the injection site and the resultant volume of label is caused by several factors. For example, although one can quantify the volume of the injection site, there is no way of knowing precisely how much dye is contained within the injection site or how much dye actually gets incorporated and anterogradely transported by IMAN neurons. Furthermore, the volume of the terminal field in each nucleus includes variations in intensity of anterograde label. Because we wished to quantify the total proportion of RA and Area X that received input from IMAN neurons, we included all levels of anterograde label in our quantitative assessment, and this source of variability also contributes to the lack of a systematic relationship between the volume of the injection site and that of the terminal field. Another important consideration is whether the density of neurons at the injection site remains constant across different ages, such that injections of similar volume would encompass comparable numbers of $1 \mathrm{MAN} \mathrm{N}_{\text {core }}$ neurons at all ages. Although the absolute number of $1 \mathrm{MAN}_{\text {core }}$ projection neurons remains constant throughout song learning, an increased density of $1 \mathrm{MAN}_{\text {core }}$ neurons in adult birds has been reported by some studies (Nordeen and Nordeen, 1988a,b; Bottjer and Sengelaub, 1989; Nordeen et al., 1992; Nixdorf-Bergweiler et al., 1995; cf. Bottjer et al., 1985; Burek et al., 1991). Thus, injections of similar volume would tend to label a slightly larger number of $1 \mathrm{MAN}_{\text {core }}$ neurons in adult birds compared with juve- niles. However, this tendency would work against the result we describe below, namely that injections into $1 \mathrm{MAN}_{\text {core }}$ of older animals actually produce more restricted patterns of anterograde label in RA.

\section{RESULTS}

Injections into $1 \mathrm{MAN}_{\text {core }}$ of all birds produced ipsilateral retrograde label in an oval region corresponding to the dorsolateral part of DLM $\left(\mathrm{DLM}_{\mathrm{DL}}\right)$ and anterograde label within ipsilateral $\mathrm{RA}$ and Area X. Injections into $1 \mathrm{MAN}_{\text {shell }}$ produced ipsilateral retrograde label in a crescent-shaped region corresponding to ventromedial DLM $\left(\mathrm{DLM}_{\mathrm{VM}}\right)$, and anterograde label in ipsilateral Ad, parolfactory lobe (LPO, the medial component of the avian striatum), and dorsal aspect of caudolateral neostriatum (dNCL, a cortical region dorsal and lateral to RA and Ad) in all groups of birds studied (Figs. 2-11). Because of limitations of space, we have not included descriptions of anterograde label over ipsilateral ventral archistriatum (Av) from RDA injections into IMAN core and shell as well as retrograde label over ipsilateral and contralateral $\mathrm{Av}$ from injections into $\mathrm{MAN}_{\text {shell }}$, which was present in all birds (Johnson et al., 1995). Control injections of either tracer placed outside the boundaries of Nissl-defined IMAN did not produce retrograde label in DLM or anterograde label in RA, Ad, or Area X at any of the ages studied. However, injections of RDA that were made lateral to the lateral border of $1 \mathrm{MAN}_{\text {shell }}$ produced anterograde label in the lateral part of LPO and $\mathrm{dNCL}$ in an adult and a $35 \mathrm{~d}$ bird (data not shown). Because injections of different fluorescent tracers into $\mathrm{MAN}_{\text {shell }}$ and the region lateral to $\mathrm{MAN}_{\text {shell }}$ were not made at any age, we could not ascertain whether these regions have overlapping terminal fields within LPO and dNCL. 


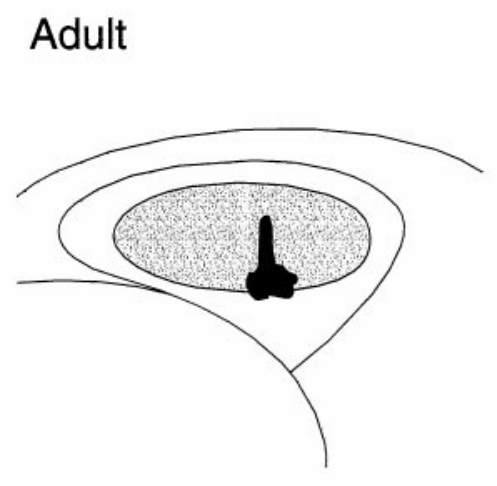

$35 d$
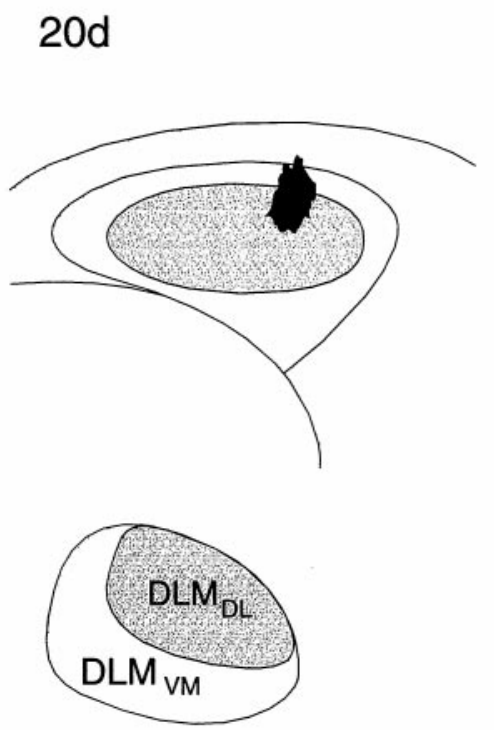
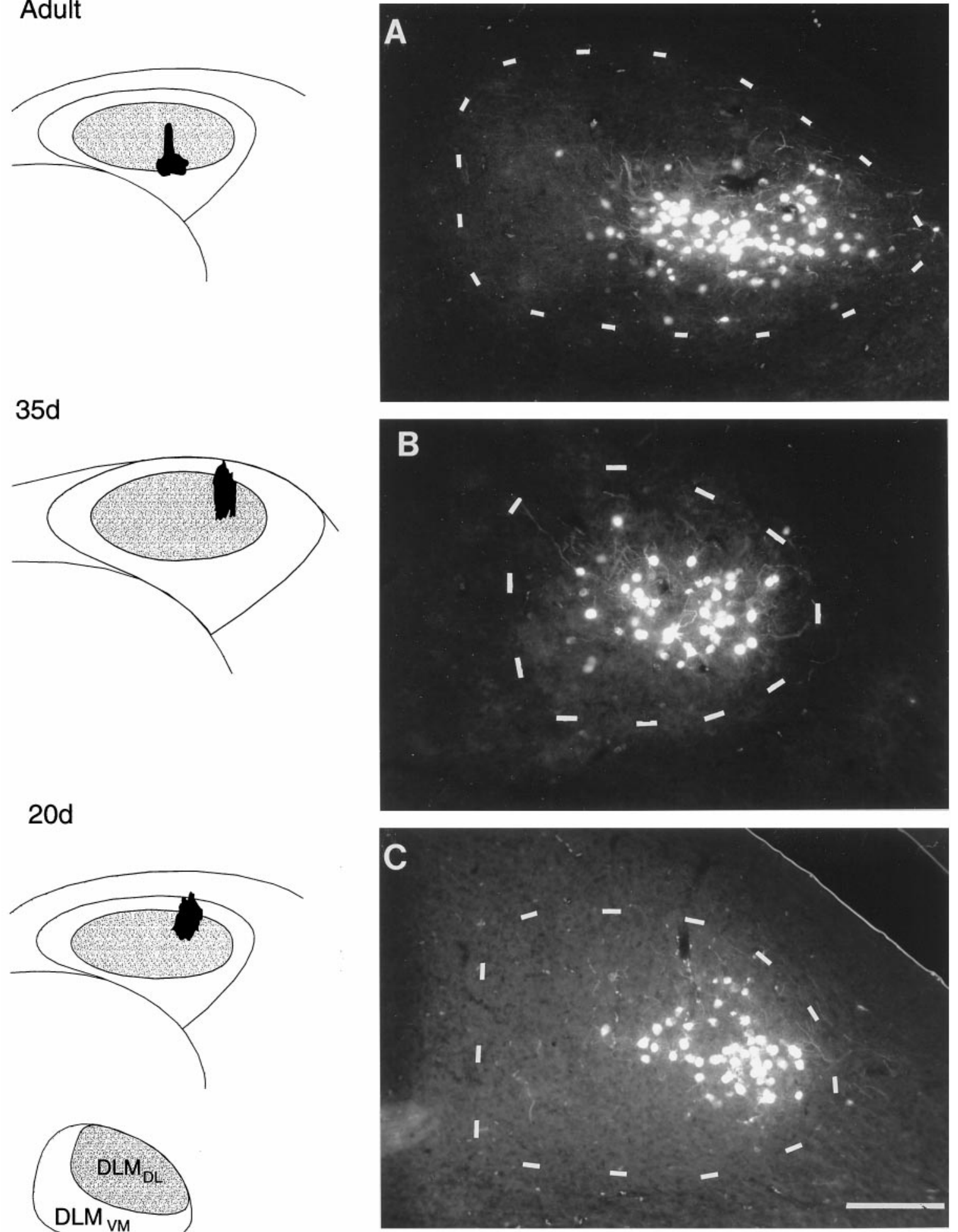

Figure 2. Photomicrographs of retrograde label within DLM produced by injections of RDA into different subregions of $1 \mathrm{MAN}_{\text {core }}$ showing comparable patterns of topography within the $\mathrm{DLM}_{\mathrm{DL}} \rightarrow \mathrm{MAN}_{\text {core }}$ circuit in birds of different ages. Injection sites in lMAN (black) are shown in coronal schematics in the left column, and dashed outlines depict Nissl-defined borders of DLM in each photomicrograph on the right. Inset (below the 1MAN schematics) demonstrates the oval dorsolateral subregion of DLM $\left(\mathrm{DLM}_{\mathrm{DL}}\right)$ and the crescent-shaped ventromedial part (DLM $\left.\mathrm{V}_{\mathrm{VM}}\right)$. $A$, Retrograde label in the ventral and intermediate parts of $\mathrm{DLM}_{\mathrm{DL}}$ resulting from an injection into ventral intermediate and lateral $1 \mathrm{MAN}_{\text {core }}$ in an adult bird. $B$, An injection of RDA into dorsolateral $1 \mathrm{MAN}_{\text {core }}$ produced retrograde label specifically within the ventral intermediate part of DLM $\mathrm{M}_{\mathrm{DL}}$ in a $35 \mathrm{~d}$ bird. $C$, RDA-labeled neurons localized to ventrolateral $\mathrm{DLM}_{\mathrm{DL}}$ from an injection into dorsolateral $\mathbf{M A N}_{\text {core }}$ in a $20 \mathrm{~d}$ bird. Retrograde label did not extend into the ventromedial subregion of DLM or into more dorsal subregions of $\mathrm{DLM}_{\mathrm{DL}}$ in any of these birds. Scale bar, $200 \mu \mathrm{m}$. 


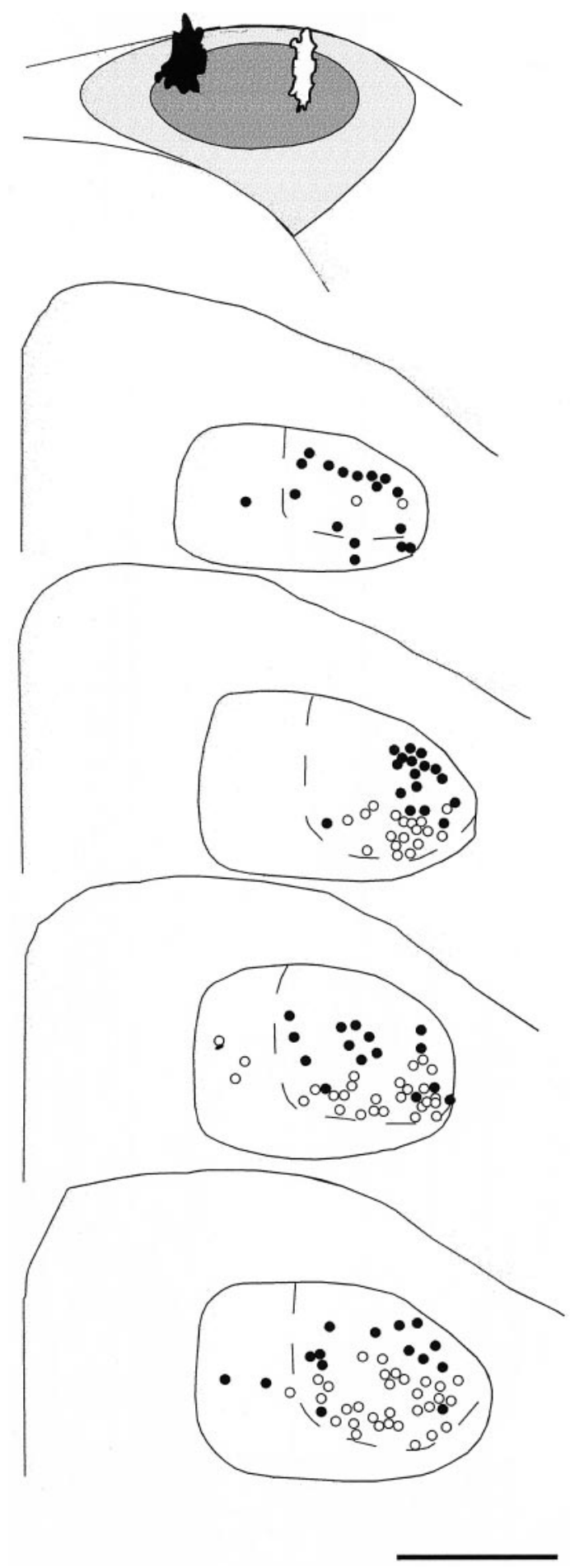

Figure 3. Camera lucida tracings of coronal sections of DLM demonstrating the dorsoventral pattern of connectivity within the $\mathrm{DLM}_{\mathrm{DL}} \rightarrow \mathrm{MAN}_{\text {core }}$ circuit in a $35 \mathrm{~d}$ bird. This bird received injections of RDA in the dorsomedial part (black injection site) and FDA in the dorsolateral part (white injection site) of $\mathrm{IMAN}_{\text {core }}$, which are depicted in the schematic at top (above DLM sections). The resulting pattern of retrograde label in serial coronal sections of DLM indicated that RDA retrogradely labeled neurons within dorsal $\mathrm{DLM}_{\mathrm{DL}}$ (black circles), whereas FDA retrogradely labeled neurons throughout ventral DLM $\mathrm{DL}_{\mathrm{DL}}$ (open circles); dashed lines delineate $\mathrm{DLM}_{\mathrm{DL}}$ from $\mathrm{DLM}_{\mathrm{VM}}$. A small number of neurons were also labeled within $\mathrm{DLM}_{\mathrm{VM}}$ as a result of both tracers extending into small parts of $1 \mathrm{MAN}_{\text {shell. }}$. Scale bar, $500 \mu \mathrm{m}$.

\section{Retrograde label in DLM}

\section{Adult birds}

When one tracer was injected into $1 \mathrm{MAN}_{\text {shell }}$ and the other tracer into $\mathrm{IMAN}_{\text {core }}$ on the same side, no double-labeled neurons were observed within ipsilateral DLM, confirming previous findings that the $\mathrm{DLM}_{\mathrm{DL}} \rightarrow 1 \mathrm{MAN}$ core and $\mathrm{DLM}_{\mathrm{VM}} \rightarrow 1 \mathrm{MAN}_{\text {shell }}$ circuits are separate, parallel pathways (cf. Johnson et al., 1995). Dye injections confined to the lateral part of $1 \mathrm{MAN}_{\text {core }}$ produced retrogradely labeled neurons within the ventralmost part of $\mathrm{DLM}_{\mathrm{DL}}$, whereas injections into intermediate and medial subregions produced retrogradely labeled neurons in intermediate and dorsal subregions of $\mathrm{DLM}_{\mathrm{DL}}$ overlying this ventral subregion, respectively. Comparing the pattern of retrograde label resulting from injections into different subregions of $1 \mathrm{MAN}_{\text {core }}$ in adult birds also revealed that dorsoventral position of the injection sites did not contribute to differences in label over DLM $\mathrm{M}_{\mathrm{DL}}$. Twentysix of a total of 26 injections into $1 \mathrm{MAN}_{\text {core }}$ (10 in lateral core, seven in intermediate core, and nine in medial core) confirmed this pattern of label in adult birds. Figure $2 A$ demonstrates retrograde label confined to a cluster of neurons in the ventral and intermediate parts of $\mathrm{DLM}_{\mathrm{DL}}$ resulting from an injection of RDA that was centered in ventral intermediate $1 M A N_{\text {core }}$ and also extended slightly into lateral $1 \mathrm{MAN}_{\text {core }}$. No neurons within $\mathrm{DLM}_{\mathrm{VM}}$ or within more dorsal parts of DLM $\mathrm{DL}_{\mathrm{DL}}$ were labeled by this injection (compare Fig. 3).

In contrast to injections into $\mathrm{MAN}_{\text {core }}$, injections into the shell region of IMAN produced retrogradely labeled neurons only within the ventromedial part of DLM. Twenty-one of 21 dye injections into lateral $1 \mathrm{MAN}_{\text {shell }}$ resulted in retrograde label over the ventral part of DLM $\mathrm{VM}_{\mathrm{M}}$, whereas nine of nine injections into medial $1 \mathrm{MAN}$ shell produced retrograde label within the medial subregion of DLM $\mathrm{VM}_{\mathrm{VM}}$. An RDA injection into lateral $1 \mathrm{MAN} \mathrm{N}_{\text {shell }}$ that produced retrograde label in a restricted area within the ventromedial part of $\mathrm{DLM}_{\mathrm{VM}}$ is shown in Figure $4 A$.

These results confirm previous findings of broad patterns of topographic organization within both of the DLM $\rightarrow$ IMAN circuits in adult male zebra finches (Johnson et al., 1995). However, the pattern of retrograde label in $\mathrm{DLM}_{\mathrm{DL}}$ resulting from injections of fluorescent tracers into $1 \mathrm{MAN}_{\text {core }}$ observed in our study indicated a more dorsoventral pattern of organization in DLM compared with the more mediolateral DLM topography emphasized by Johnson et al. (1995). Although our results indicated some degree of mediolateral topography within the $\mathrm{DLM}_{\mathrm{DL}} \rightarrow \mathrm{MAN}_{\text {core }}$ circuit, the dorsoventral axis of $\mathrm{DLM}_{\mathrm{DL}}$ appeared to be mapped out primarily along the mediolateral axis within $1 \mathrm{MAN}_{\text {core }}$. It is possible that we found a slightly different pattern of label within this circuit because our injections encompassed smaller subregions within $1 \mathrm{MAN}$ core

Juvenile birds (35 and 20 d)

Injections of RDA and FDA into IMAN core and shell of juvenile birds ( 35 and $20 \mathrm{~d}$ ) revealed a pattern of retrograde label in DLM comparable to that found in adults: injections into $1 \mathrm{MAN}_{\text {core }}$ produced retrogradely labeled neurons in $\mathrm{DLM}_{\mathrm{DL}}$, whereas dye injections into $1 \mathrm{MAN}_{\text {shell }}$ retrogradely labeled neurons in $\mathrm{DLM}_{\mathrm{VM}}$. Double-labeled neurons were never seen in these birds after injections of different dyes into $1 \mathrm{MAN} \mathrm{N}_{\text {core }}$ and $1 \mathrm{MAN} \mathrm{N}_{\text {shell }}$ on the same side, indicating that the $\mathrm{DLM}_{\mathrm{DL}} \rightarrow \mathrm{IMAN}_{\text {core }}$ and $\mathrm{DLM}_{\mathrm{VM}} \rightarrow \mathrm{IMAN}_{\text {shell }}$ circuits exist as discrete pathways at the initiation of song learning (18-22 d after hatching). Twenty-five of 25 injections into $1 \mathrm{MAN}_{\text {core }}$ (nine lateral, six intermediate, and 10 medial core injections) and 26 of 26 injections into $1 \mathrm{MAN}_{\text {shell }}$ 

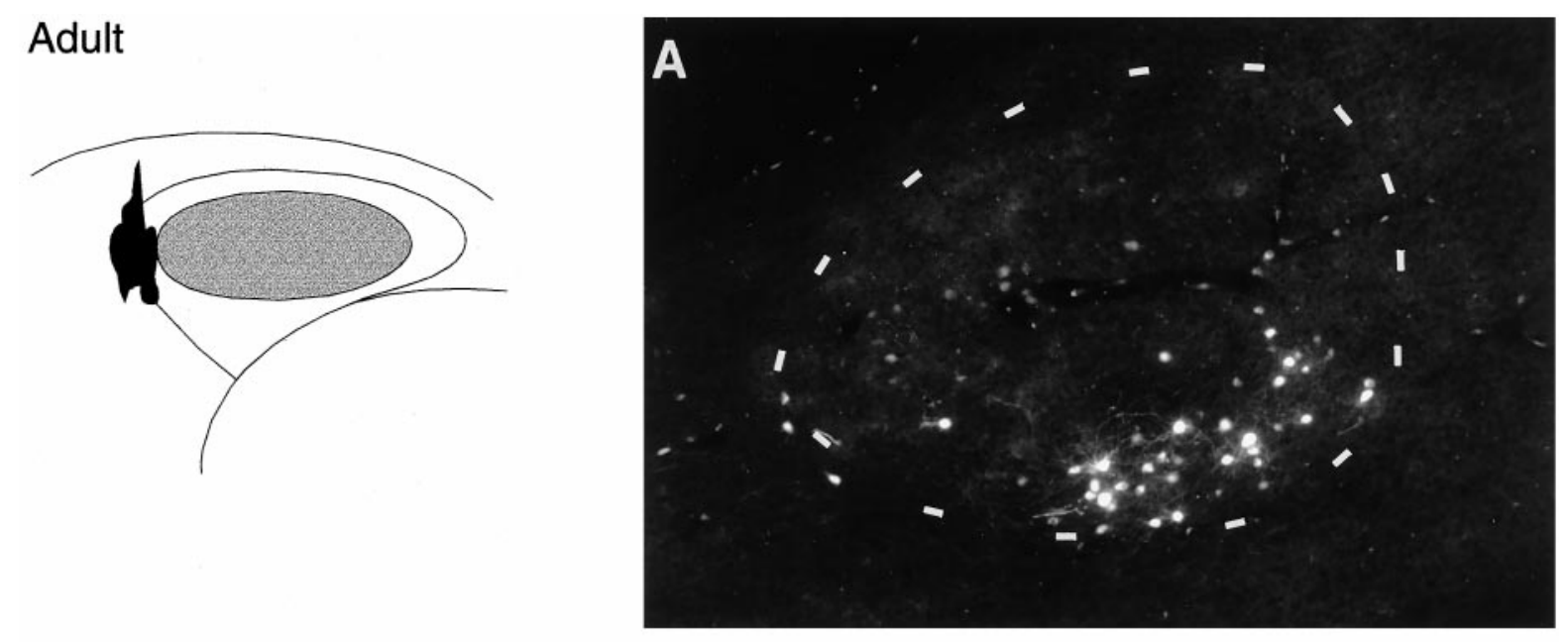

\section{$35 d$}
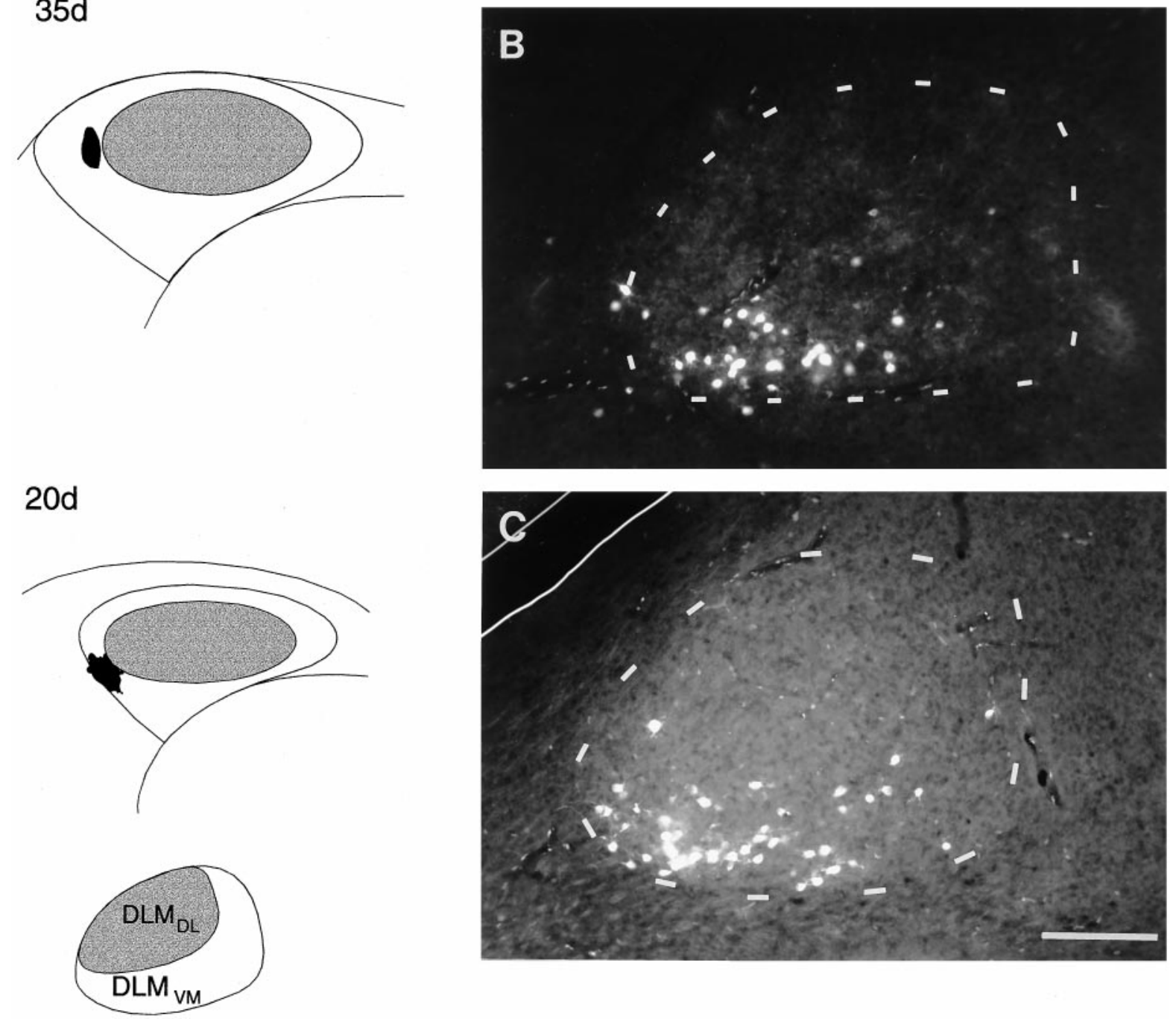

Figure 4. Photomicrographs demonstrating comparable patterns of connectivity within the $\mathrm{DLM}_{\mathrm{VM}} \rightarrow 1 \mathrm{MAN}$ shell projection in adult, $35 \mathrm{~d}$, and $20 \mathrm{~d}$ birds. Injections of RDA into the lateral part of left $\mathrm{IMAN}_{\text {shell }}$ (shown in schematics on the left) resulted in retrograde label within coronal sections (on right). $A$, Retrogradely labeled cells in the ventromedial region of $\mathrm{DLM}_{\mathrm{VM}}$ in an adult bird; faint FDA-labeled neurons can also be seen in DLM $\mathrm{DL}$ in this photomicrograph because FDA, which was injected into $\mathrm{MAN}_{\text {core }}$, emits a small amount of fluorescence under rhodamine optics. $B, C$, Retrograde label was present in ventrolateral and ventral intermediate parts of DLM $\mathrm{VM}_{\mathrm{M}}$ in a 35 and a $20 \mathrm{~d}$ bird, respectively. Scale bar, $200 \mu \mathrm{m}$. 
(A) Adult

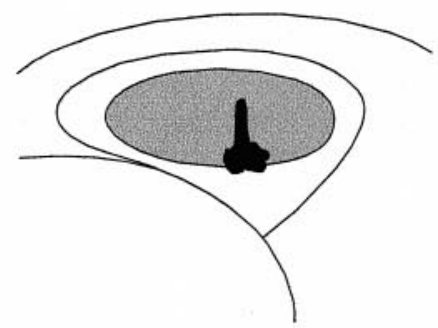

(C)
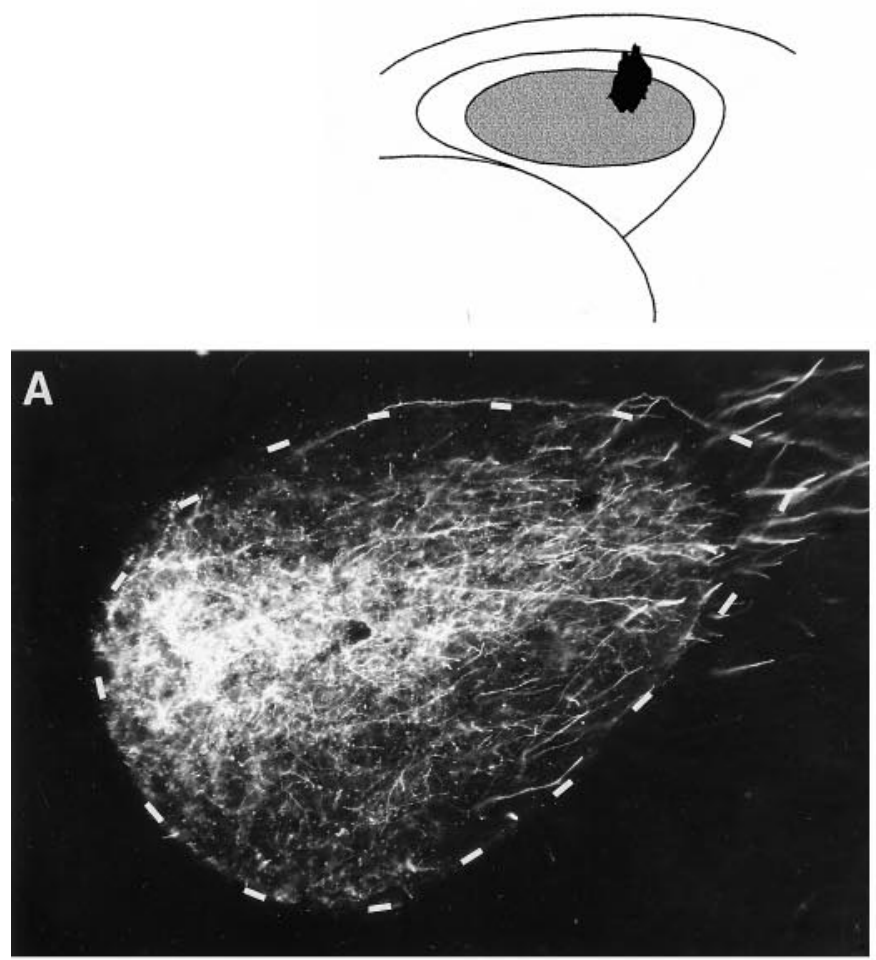

C

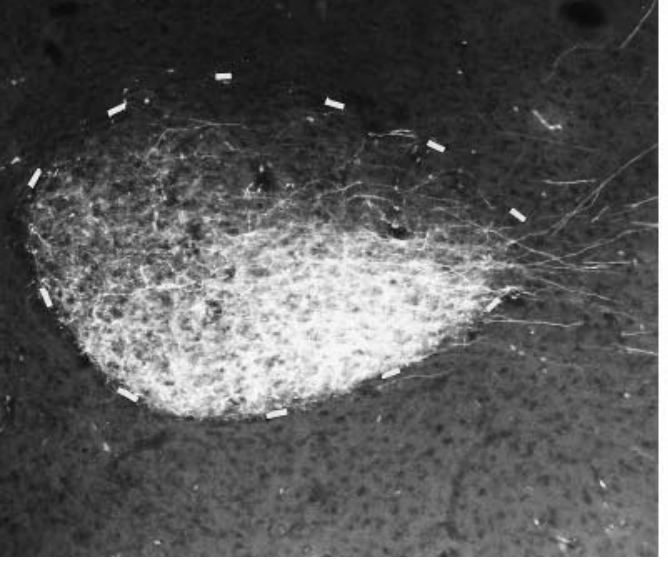

(B) $35 d$

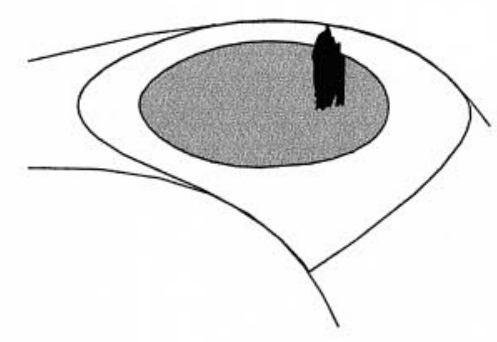

(D) $20 \mathrm{~d}$
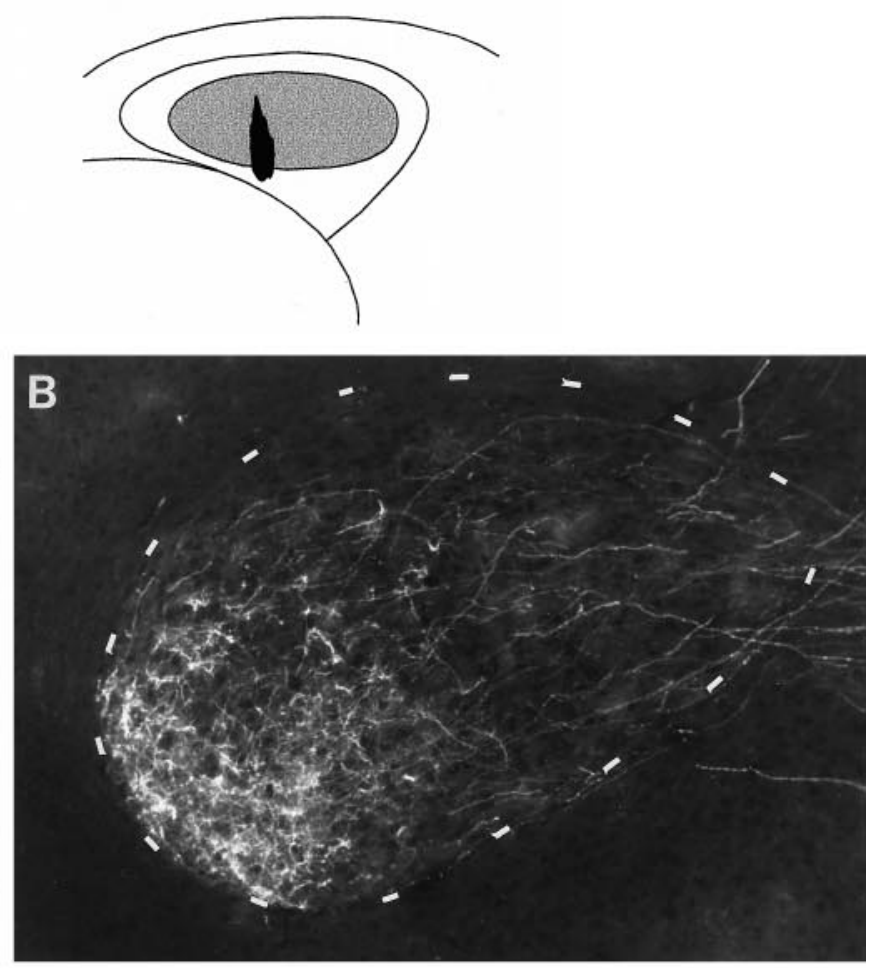

D

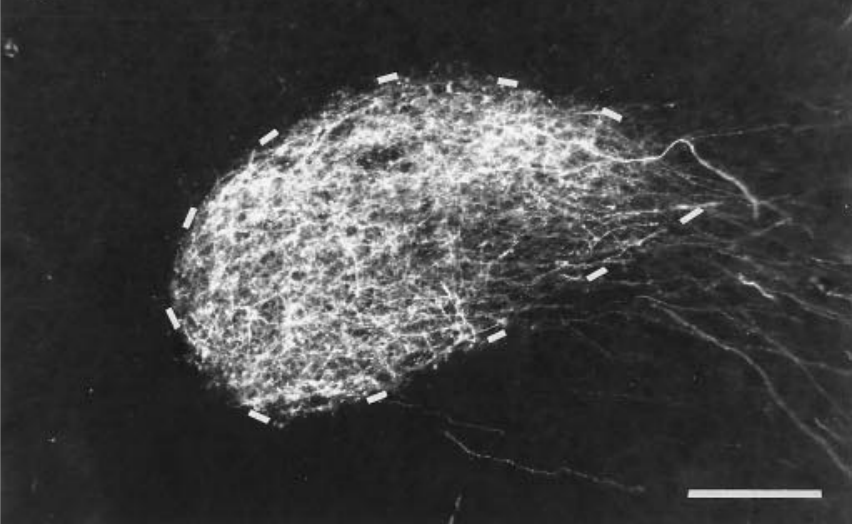



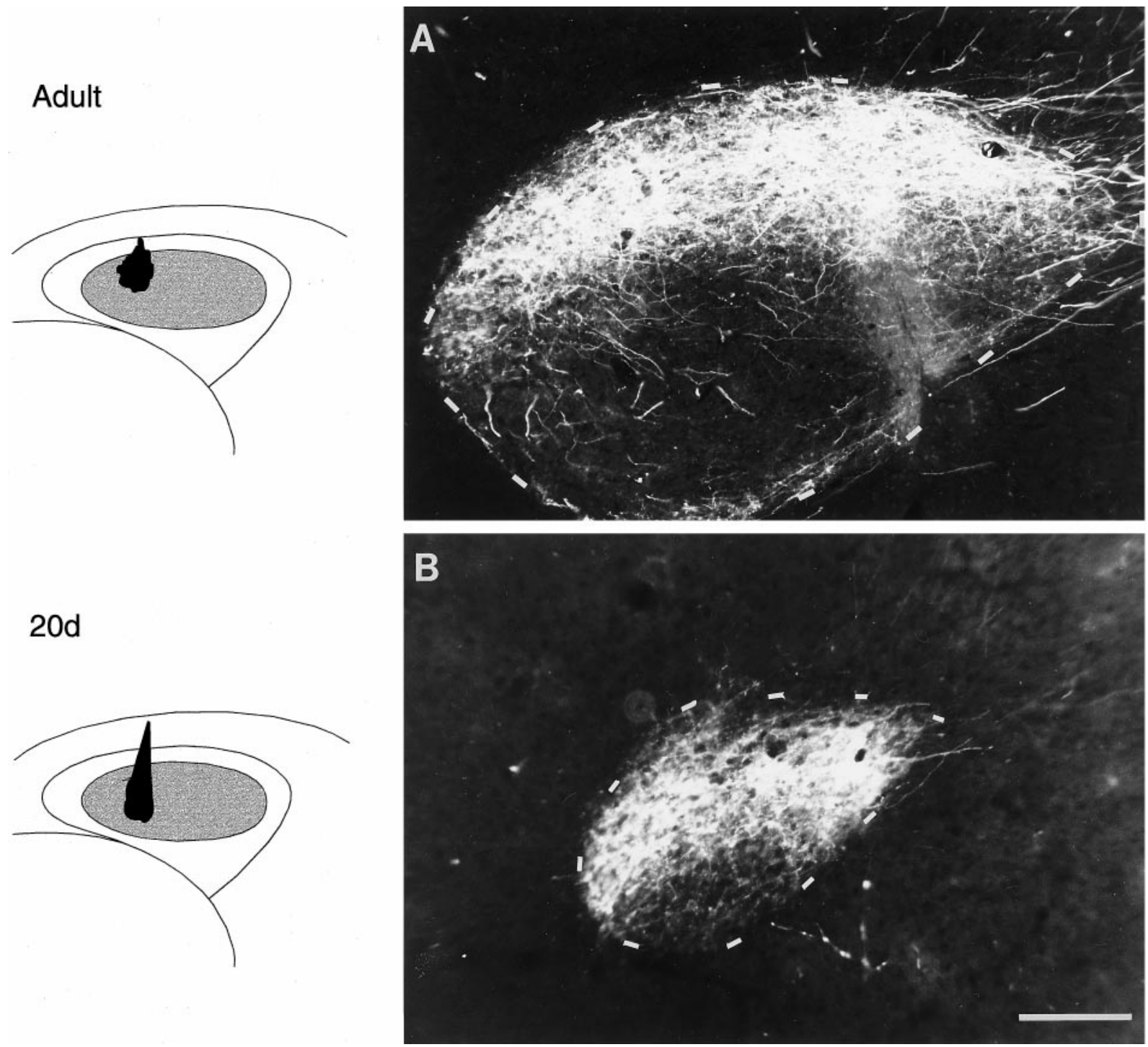

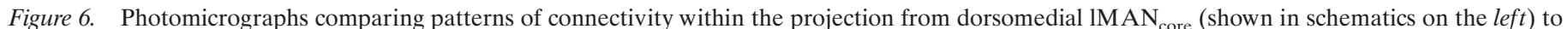
the dorsal part of RA (coronal sections) in an adult and a $20 \mathrm{~d}$ bird. $A$, The majority of RDA-labeled axons enter the lateral margin of RA and arborize within the dorsal "cap" region in an adult bird. $B$, An injection into the dorsomedial part of $\mathrm{MMAN}_{\text {core }}$ of a $20 \mathrm{~d}$ bird that extended slightly into ventromedial $1 \mathrm{MAN}_{\text {core }}$ produced anterograde label over the dorsal and intermediate part of RA as well as the underlying ventromedial and ventrolateral parts. A very small region within the dorsalmost part of RA in this bird was covered by very sparse anterograde label. Scale bar, $200 \mu \mathrm{m}$.

(16 lateral and 10 medial) of $20 \mathrm{~d}$ birds produced patterns of retrograde label in $\mathrm{DLM}_{\mathrm{DL}}$ and $\mathrm{DLM}_{\mathrm{VM}}$ respectively, which were comparable to those in adults. Furthermore, the projections from DLM to IMAN core and shell remain as separate pathways at $35 \mathrm{~d}$ after hatching (Figs. $2 B, 4 B$ ), an age at which there is a dramatic increase in the volume of the overall DLM terminal field which encompasses $1 \mathrm{MAN}_{\text {shell }}$ (Johnson and Bottjer, 1992). Thus, despite the considerable axonal re-arrangement suggested by the growth of the projection of DLM to IMAN $_{\text {shell }}$ (Iyengar and Bottjer, 1998), axons of individual DLM neurons still respect the boundaries of core and shell regions in IMAN. Thirteen of 13 injections (eight lateral, two intermediate, and three medial) into $1 \mathrm{MAN}_{\text {core }}$ and 15 of 15 injections (nine lateral and six medial) into $1 \mathrm{MAN}_{\text {shell }}$ of $35 \mathrm{~d}$ birds were used to confirm these patterns of retrograde label in $\mathrm{DLM}_{\mathrm{DL}}$ and $\mathrm{DLM}_{\mathrm{VM}}$, respectively.

The topographic organization within each DLM $\rightarrow$ IMAN cir-

\section{$\leftarrow$}

Figure 5. Photomicrographs of anterograde label over coronal sections of RA resulting from injections of RDA into right $1 \mathrm{MAN}$ core showing patterns of connectivity within the $\mathrm{IMAN}_{\text {core }} \rightarrow \mathrm{RA}$ projection in adult, $35 \mathrm{~d}$, and $20 \mathrm{~d}$ birds (cf. Johnson et al., 1995). Nissl-defined boundaries of RA are depicted by dashed outlines, and injection sites within $\mathrm{MANN}_{\text {core }}$ for each bird are shown in schematics. $A$, An injection of RDA into ventral intermediate and lateral $\mathrm{MAN}_{\text {core }}$ produced anterograde label restricted to a triangular region within the medial and central regions of RA in an adult bird. $B$, Anterograde label localized to the ventromedial subregion of RA produced by an injection into dorsolateral $1 \mathrm{MAN}$ core in a $35 \mathrm{~d}$ bird. $C$, An injection of RDA within the dorsolateral subregion of $1 \mathrm{MAN}_{\text {core }}$ which extended slightly into its intermediate subregion in a $20 \mathrm{~d}$ bird produced anterograde label encompassing both ventromedial and ventrolateral parts of RA. The only region devoid of label within RA was the dorsal "cap" region. $D$, An injection in the ventral intermediate subregion of $1 \mathrm{MAN}_{\text {core }}$ of another $20 \mathrm{~d}$ bird produced anterograde label throughout RA except for a very small region along its ventrolateral border. Scale bar, $200 \mu \mathrm{m}$. 

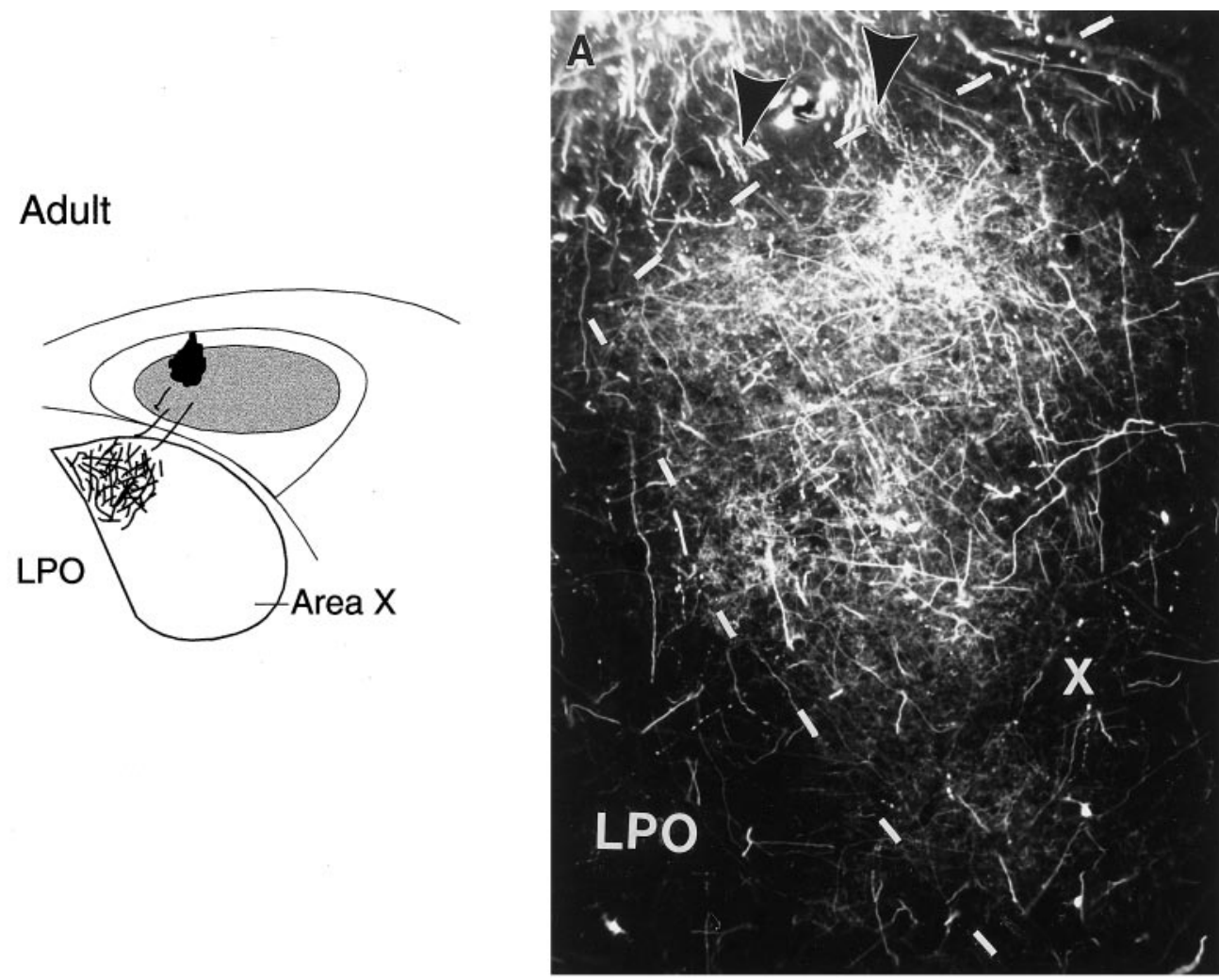

\section{0d}

Figure 7. Injections of RDA into different subregions of right $1 \mathrm{MAN}_{\text {core }}$ (shown in schematics on the left) produced anterograde label over specific regions within coronal sections of Area X (schematics and photomicrographs). $A$, An injection into dorsomedial $\mathrm{IMAN}_{\text {core }}$ in an adult bird resulted in anterograde label over the medial part of Area X (dashed outlines delineate medial and dorsal borders of Area X from the surrounding LPO). $B$, In a $20 \mathrm{~d}$ bird, an
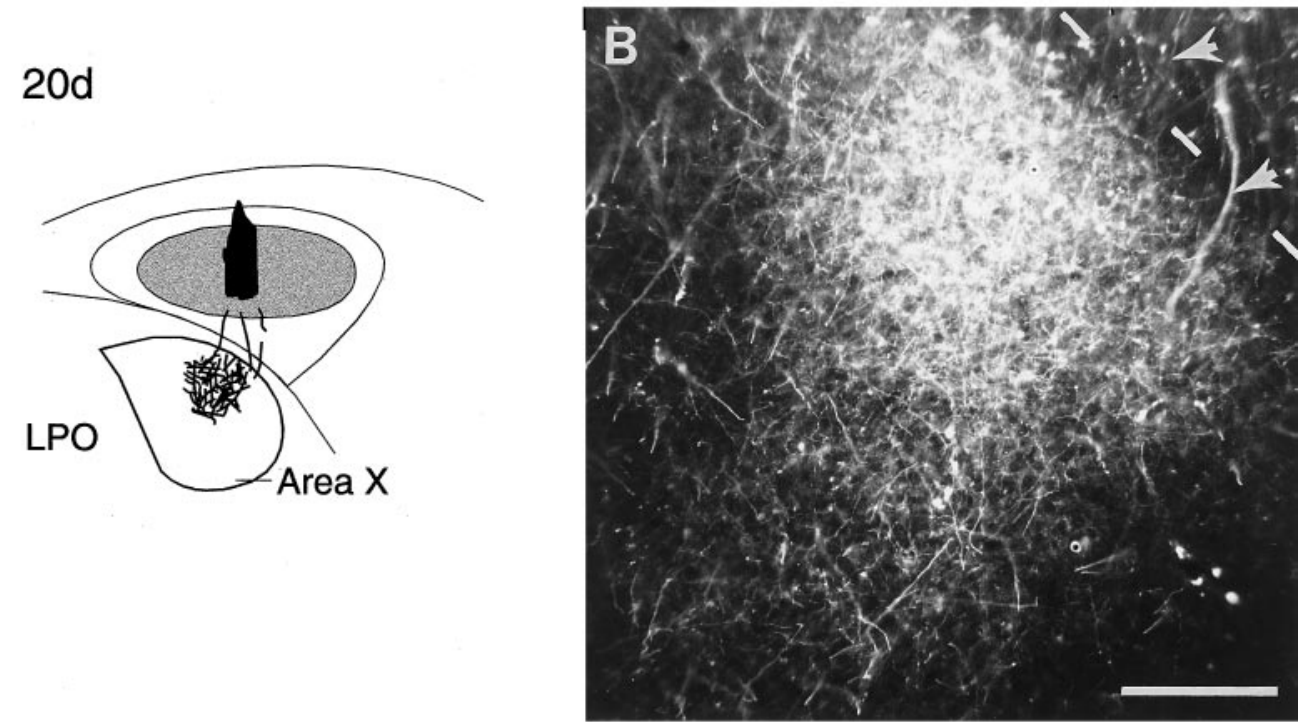
injection into intermediate $1 \mathrm{MAN}_{\text {core }}$ produced anterograde label over the intermediate part of Area X. Arrows in both photomicrographs indicate RDA-labeled axons from $1 \mathrm{MAN}_{\text {core }}$ that cross the fiber tract LMD to enter and arborize within Area X. Scale bar, $200 \mu \mathrm{m}$.

cuit in juvenile birds was comparable to the patterns of topography seen in adult males. Injections of either tracer into lateral, intermediate, or medial subregions of $1 \mathrm{MAN}_{\text {core }}$ in juvenile birds of both age groups produced retrograde label restricted to ventral, intermediate, or dorsal parts of $\mathrm{DLM}_{\mathrm{DL}}$, respectively. An example of this pattern of topography is seen in Figure 2, $B$ and $C$, where injections of RDA into lateral $1 \mathrm{MAN} \mathrm{N}_{\text {core }}$ of a 35 and a $20 \mathrm{~d}$ bird produced restricted groups of retrogradely labeled neurons in the midventral (Fig. $2 B$ ) and lateroventral parts of $\mathrm{DLM}_{\mathrm{DL}}$ (Fig. 2C). Retrograde label did not extend into dorsal and intermediate parts of $\mathrm{DLM}_{\mathrm{DL}}$ in either of the juvenile birds, indicating that the $\mathrm{DLM}_{\mathrm{DL}} \rightarrow \mathrm{IMAN}_{\text {core }}$ pathway is topographically organized at both these ages in a manner similar to that seen in adults. A $35 \mathrm{~d}$ bird received injections of both RDA and FDA into medial and lateral subregions of $1 \mathrm{MAN}_{\text {core }}$, respectively (Fig. 3). Camera lucida tracings of the resultant retrograde label in serial sections of $\mathrm{DLM}_{\mathrm{DL}}$ demonstrated a primarily dorsoventral pattern that was also seen in adult birds: RDA from medial $1 \mathrm{MAN}_{\text {core }}$ retrogradely labeled neurons primarily in the dorsal aspect of $\mathrm{DLM}_{\mathrm{DL}}$, whereas FDA from lateral $1 \mathrm{MAN}_{\text {core }}$ retrogradely labeled neurons throughout ventral $\mathrm{DLM}_{\mathrm{DL}}$. A small number of neurons were also labeled in $\mathrm{DLM}_{\mathrm{VM}}$, resulting from tracers extending into small parts of dorsal $1 \mathrm{MAN}_{\text {shell }}$.

Small dye injections into lateral or medial subregions of $1 \mathrm{MAN} \mathrm{N}_{\text {shell }}$ in juvenile birds retrogradely labeled neurons restricted to ventral and medial subregions of DLM, respectively. Figure 4, $B$ and $C$, demonstrates the pattern of retrograde label in $\mathrm{DLM}_{\mathrm{VM}}$ produced by injections of RDA into lateral $1 \mathrm{MAN} \mathrm{N}_{\text {shell }}$ in 

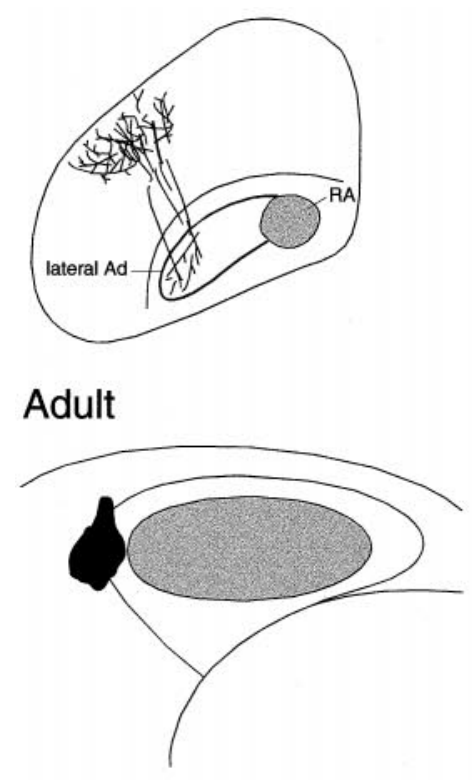

$35 d$

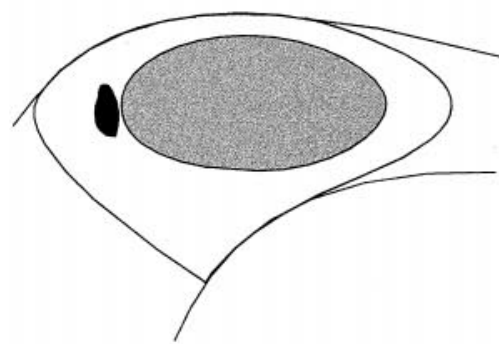

$20 d$

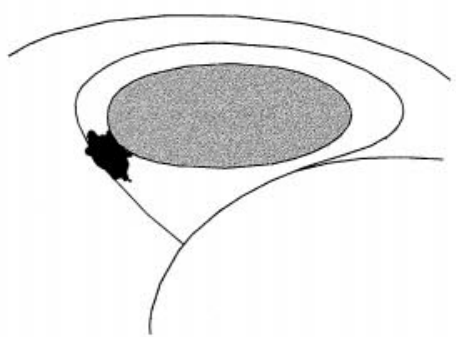

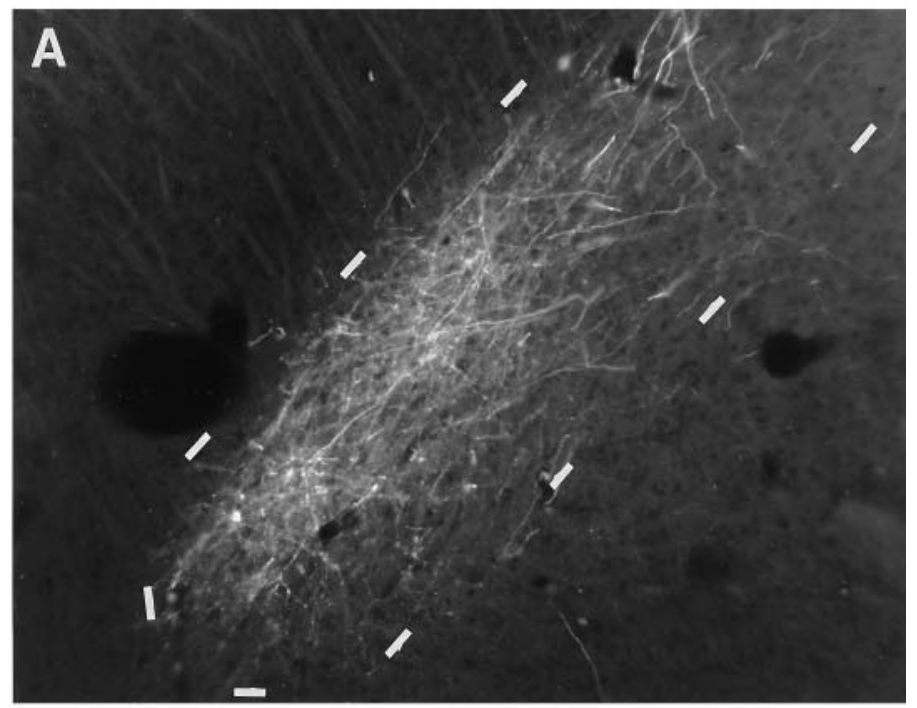
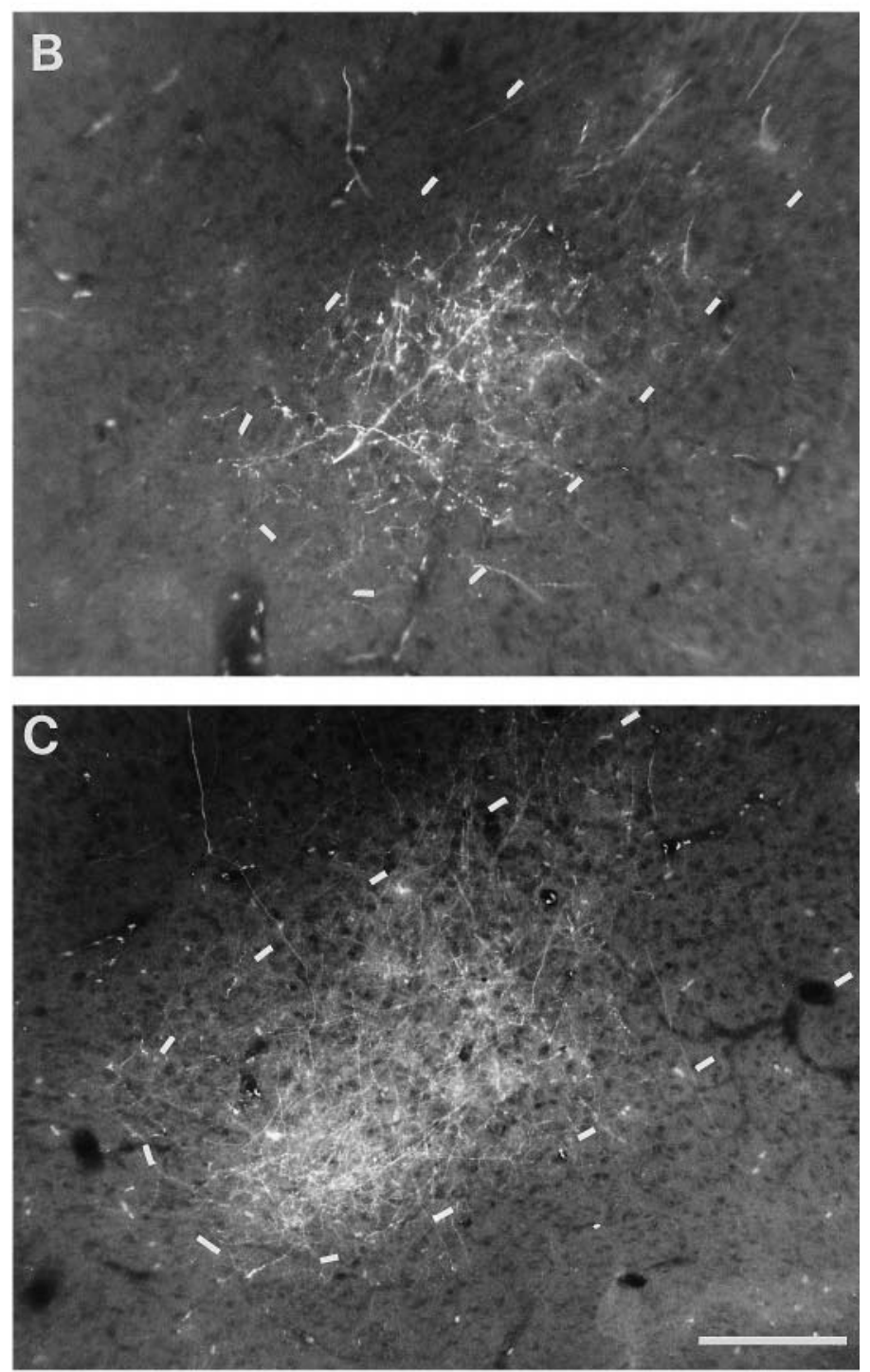

Figure 8. Anterograde label over Ad (Nissl-defined borders indicated by dashed outlines in coronal sections) resulting from injections of RDA into the lateral part of left $1 \mathrm{MAN}_{\text {shell }}$ indicate that the $\mathrm{lMAN}_{\text {shell }} \rightarrow$ Ad circuit is comparable in an adult $(A)$, a $35 \mathrm{~d}(B)$, and a $20 \mathrm{~d}(C)$ bird. Schematic diagrams on the left demonstrate injection sites. In all three birds, anterogradely labeled axons from lateral IMAN $\mathrm{N}_{\text {shell }}$ crossed the dorsal border of lateral Ad, whereas others entered intermediate Ad and turned laterally to arborize specifically within lateral Ad (also see inset above schematics of injection sites). Scale bar, $200 \mu \mathrm{m}$. 


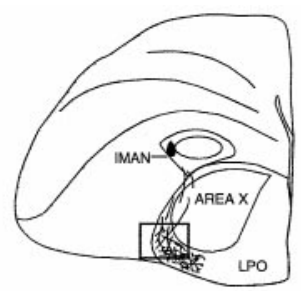

Adult

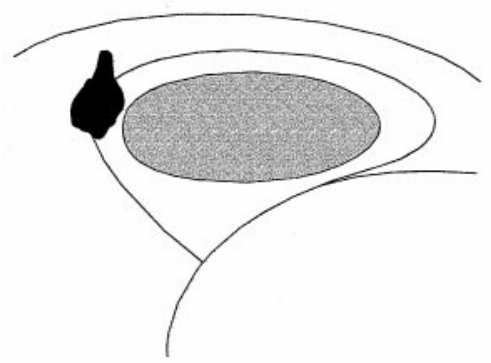

$35 d$

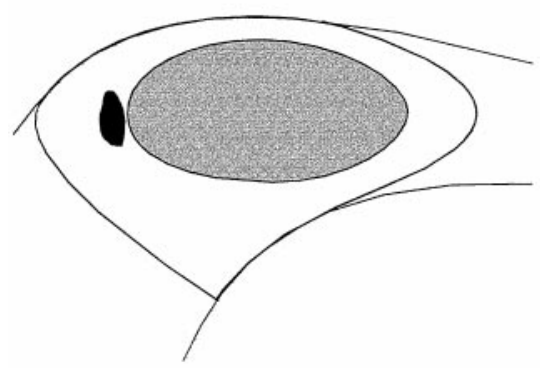

$20 d$

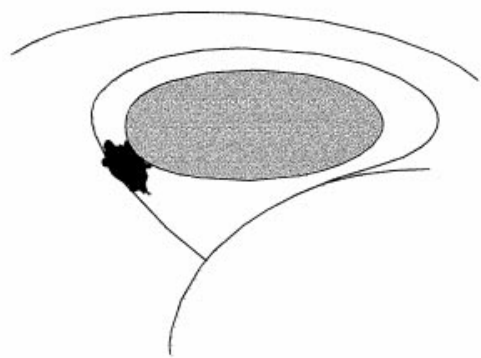

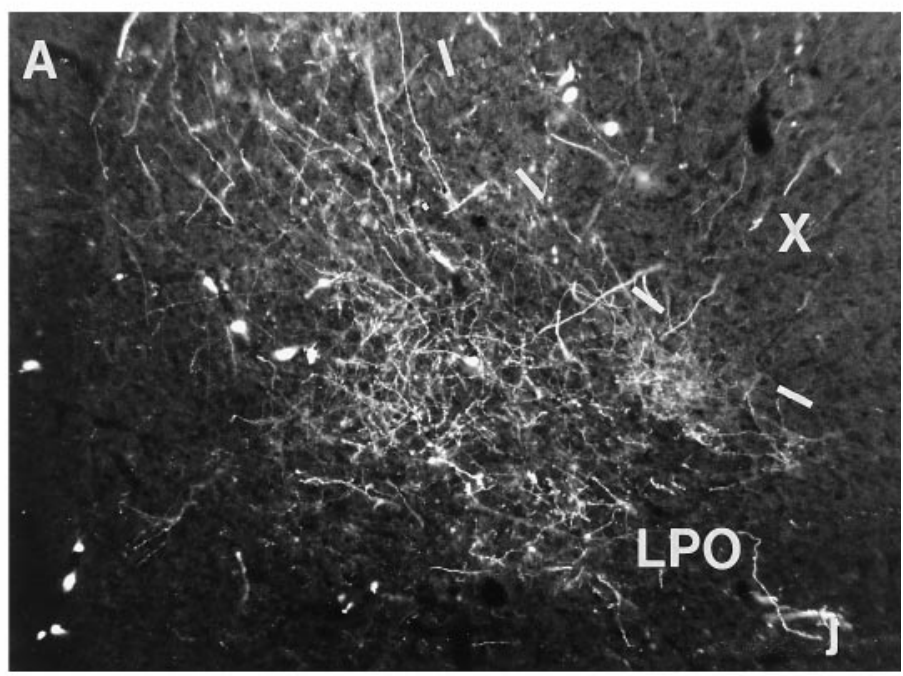
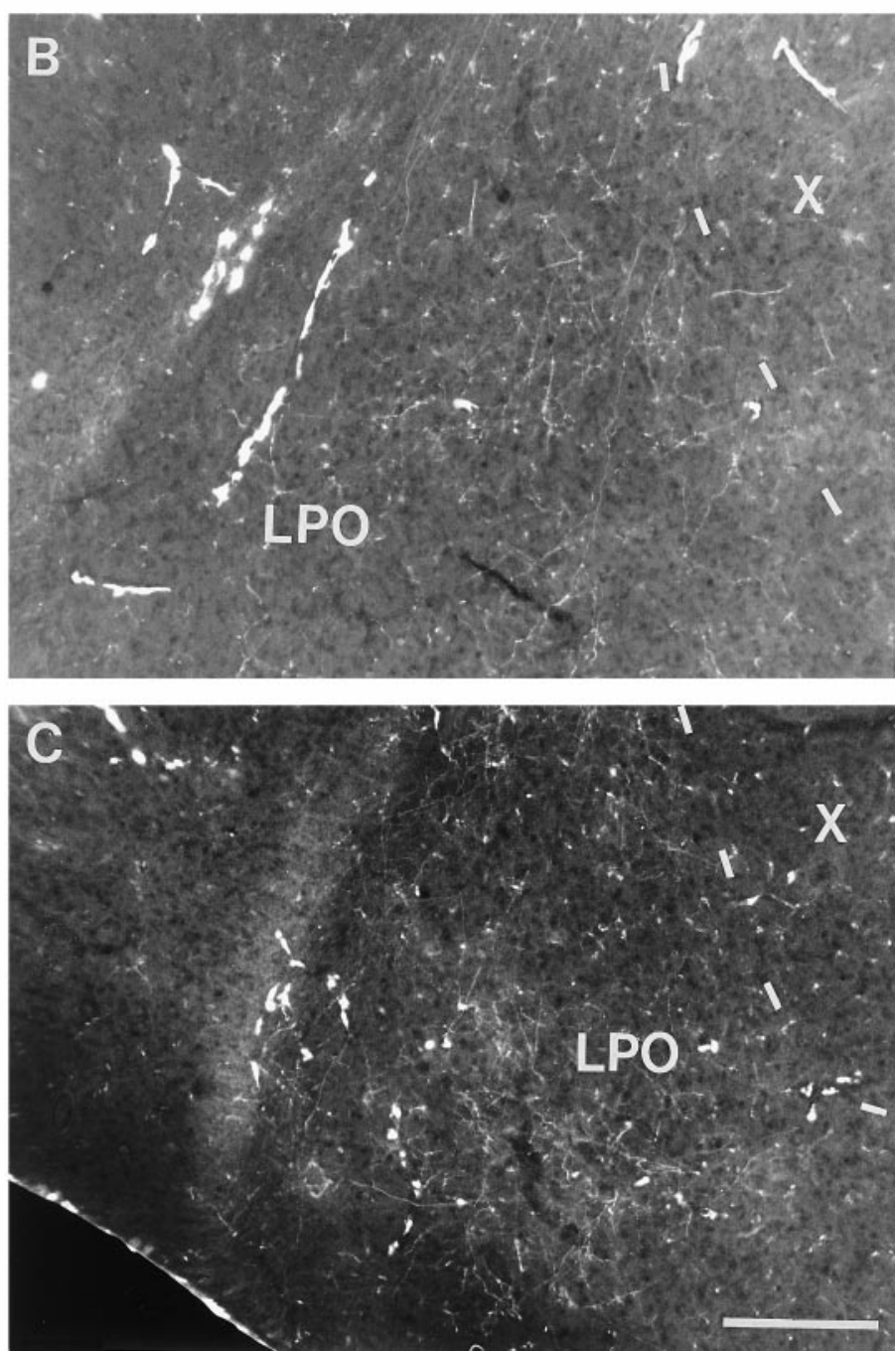

Figure 9. Photomicrographs depicting anterograde label over lateral LPO resulting from injections of RDA into the lateral part of left $1 \mathrm{MAN}$ shell in adult $(A), 35 \mathrm{~d}(B)$, and $20 \mathrm{~d}(C)$ birds. Inset (above schematics showing injection sites) depicts a coronal section of the brain at the level of $1 \mathrm{MAN} / \mathrm{Area}$ $\mathrm{X}$ showing RDA-labeled arbors in the ventrolateral aspect of LPO. The $1 \mathrm{MAN}_{\text {shell }} \rightarrow$ LPO circuit has not been reported previously. Scale bar, $200 \mu \mathrm{m}$. 
SHELL

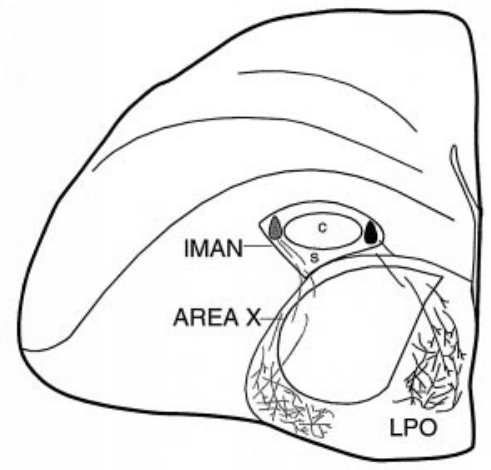

B

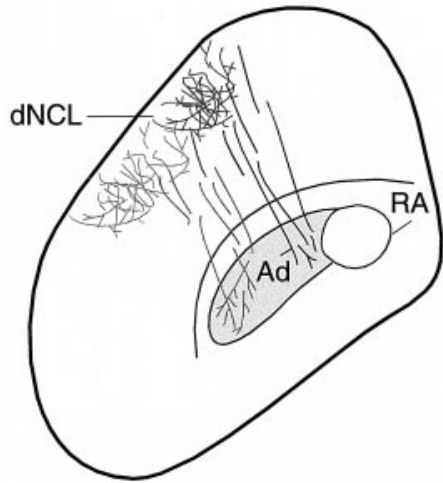

CORE
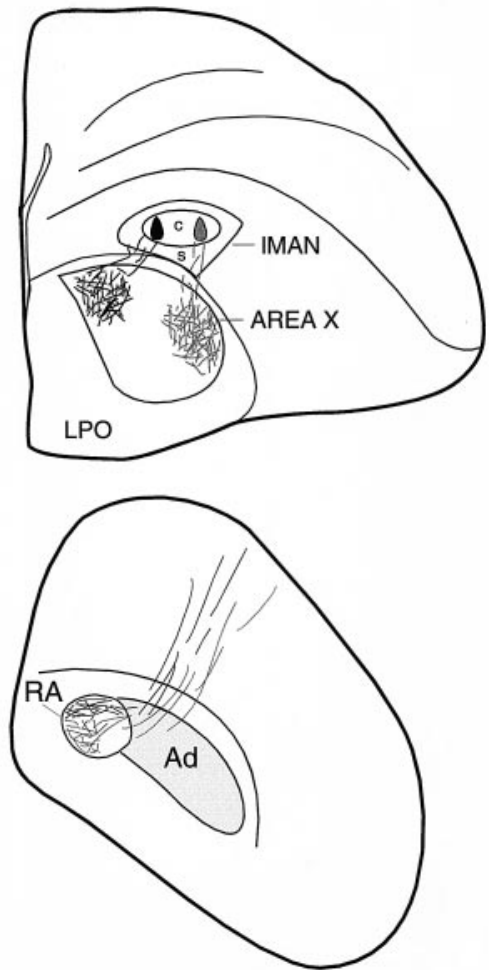

Figure 10. Schematic cross sections of the telencephalon at two different levels demonstrating overall patterns of topography within the efferent targets of $1 \mathrm{MAN}_{\text {core }}$ (Area $\mathrm{X}$ and $\mathrm{RA}$ ) and $1 \mathrm{MAN}_{\text {shell }}$ (LPO, Ad, and dNCL) in an adult zebra finch after injections of fluorescent tracers into different subregions of IMAN core and shell. Injections of tracers into lateral and medial $1 \mathrm{MAN}_{\text {core }}$ (right hemisphere in $A$ ) produced anterograde label over corresponding lateral and medial subregions of right Area X (cf. Vates and Nottebohm, 1995). B, These injections also produced label restricted to the ventromedial and dorsal subregions of ipsilateral RA, respectively (cf. Johnson et al., 1995). Injections of fluorescent tracers into lateral and medial subregions of $1 \mathrm{MAN}_{\text {shell }}$ (left hemisphere in $A$ ) resulted in anterograde label over lateral and medial parts of LPO, respectively. B, Left hemisphere, Anterograde label was also localized over the lateral parts of Ad and $\mathrm{ANCL}$ from the injection into lateral $1 \mathrm{MAN}_{\text {shell }}$ and over the medial subregions of $\mathrm{Ad}$ and $\mathrm{dNCL}$ from injections into medial $1 \mathrm{MAN}_{\text {shell}}$. Labeled $1 \mathrm{MAN}_{\text {shell }}$ axons can be seen traversing the terminal field within dNCL or travelling medial to it en route to Ad. Injection sites in medial IMAN core and shell and the resulting anterograde label are shown in black, whereas injection sites in lateral IMAN core and shell and the resulting label from these injections are shown in gray. juvenile birds at 35 and $20 \mathrm{~d}$ of age. In both cases, retrograde label was confined to a restricted subset of neurons within the ventral part of DLM $\mathrm{VM}_{\mathrm{VM}}$. Comparisons of Figure 4, $B$ and $C$, with Figure $4 A$ demonstrate that the pattern of topographic organization in the $\mathrm{DLM}_{\mathrm{VM}} \rightarrow \mathrm{IMAN}_{\text {shell }}$ of 35 and $20 \mathrm{~d}$ birds is also comparable to that seen in adult birds. Overall, these findings indicate that the topographic pattern seen within both DLM $\rightarrow$ IMAN circuits in adults is already present at the initiation of vocal development (20 d) and is maintained throughout the course of song learning.

Anterograde label in RA, Area X, Ad, LPO, and dNCL Topographic organization of the $I M A N_{\text {core }} \rightarrow R A$ circuit Adult birds. The $\mathrm{IMAN}_{\text {core }} \rightarrow \mathrm{RA}$ circuit is topographically organized in adult male zebra finches such that ventromedial, ventrolateral, and dorsal regions of RA receive projections from lateral, intermediate, and medial subregions of $1 \mathrm{MAN}_{\text {core }}$, respectively (Johnson et al., 1995). Eleven of 11 RDA injections into $\mathrm{IMAN}_{\text {core }}$ (three lateral, four intermediate, and four medial injections) in the present study confirmed this pattern of anterograde label over RA. We extended this pattern of results to include five injections in intermediate-lateral $1 \mathrm{MAN}_{\text {core }}$, all of which produced label over medial and central parts of RA in adult birds. In addition, two injections targeted to intermediate-medial $1 \mathrm{MAN}_{\text {core }}$ produced label in dorsal RA as well as in small regions extending along the medial and lateral borders just ventral to this dorsal "cap". A comparison of anterograde label resulting from injections in $1 \mathrm{MAN}_{\text {core }}$ in adult birds also revealed that dorsoventral position of the injection sites did not contribute to differences in label over RA. Specific examples of topographic patterns within the $\mathrm{IMAN}_{\text {core }} \rightarrow \mathrm{RA}$ circuit in adult birds will be described in relation to the pattern of topography seen in this circuit in $20 \mathrm{~d}$ birds in the following section.

Comparison between patterns of topography in $I M A N_{\text {core }} \rightarrow R A$ circuit in $20 d$ and adult birds. In contrast to the restricted topo- graphic pattern of the $\mathrm{IMAN}_{\text {core }} \rightarrow \mathrm{RA}$ circuit in adult male zebra finches, small injections of RDA targeted to different subregions of $1 \mathrm{MAN} \mathrm{N}_{\text {core }}$ in $20 \mathrm{~d}$ zebra finches produced a poorly refined pattern of connectivity in RA. Whereas injections into specific parts of $1 \mathrm{MAN}_{\text {core }}$ in adult birds produced anterograde label localized to restricted subregions of RA, comparable injections into $\mathrm{IMAN}_{\text {core }}$ of $20 \mathrm{~d}$ birds produced label that ramified much more extensively within RA. This pattern of results was seen in 19 of a total of 20 injections analyzed in $20 \mathrm{~d}$ birds (four lateral, five intermediate, nine medial, and two lateral-intermediate injections) in $1 \mathrm{MAN}_{\text {core }}$.

For example, an injection into dorsolateral $1 \mathrm{MAN}_{\text {core }}$ that also extended slightly into intermediate $\mathrm{IMAN}_{\text {core }}$ in a $20 \mathrm{~d}$ bird produced anterograde label encompassing both ventrolateral and ventromedial regions of RA (Fig. 5C). The only region within RA that was completely devoid of anterograde label in this bird was the dorsal cap, the area that receives projections from the medial part of $1 \mathrm{MAN}_{\text {core }}$ in adult birds (Fig. 6A). A comparison of the pattern of label in RA in this bird (Fig. $5 C$ ) with that of an adult bird that received an injection of comparable size into $\mathrm{IMAN}_{\text {core }}$ (Fig. $5 A$ ) demonstrates the difference between the $1 \mathrm{MAN}_{\text {core }} \rightarrow \mathrm{RA}$ circuit at these two ages. In the adult bird, a small dye injection into ventral regions of lateral and intermediate $\mathrm{IMAN}_{\text {core }}$ produced a terminal field restricted to medial and central subregions of RA. Most of the labeled axons from $\mathrm{IMAN}_{\text {core }}$ neurons in this bird entered lateral RA, whereas a small number of axons also entered its dorsal and ventrolateral subregions. However, all labeled $1 \mathrm{MAN}$ core axons arborized in a restricted region within medial and central portions of RA. Although these injections in the $20 \mathrm{~d}$ and adult bird are matched for size and mediolateral site within $\mathrm{IMAN}_{\text {core }}$, the injection in the $20 \mathrm{~d}$ bird is located within dorsal $1 \mathrm{MAN} \mathrm{N}_{\text {core }}$ as opposed to ventral $1 \mathrm{MAN} \mathrm{N}_{\text {core }}$ in the adult bird. However, we observed no tendency for the pattern of 


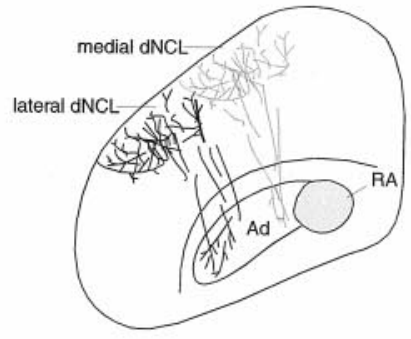

Adult

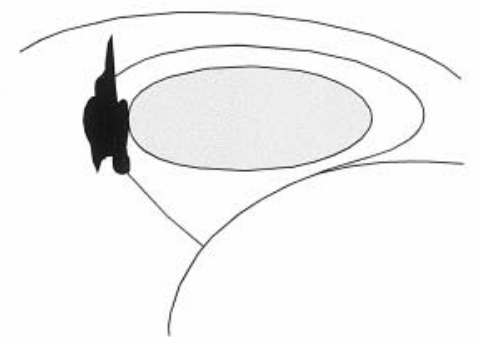

$35 d$

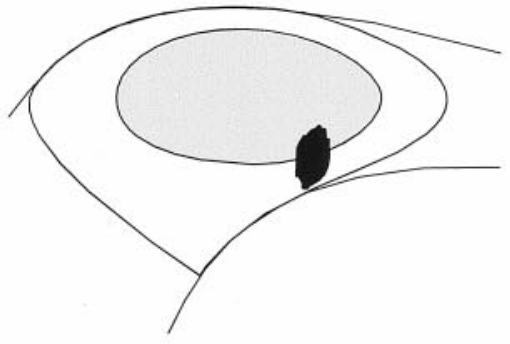

$20 d$

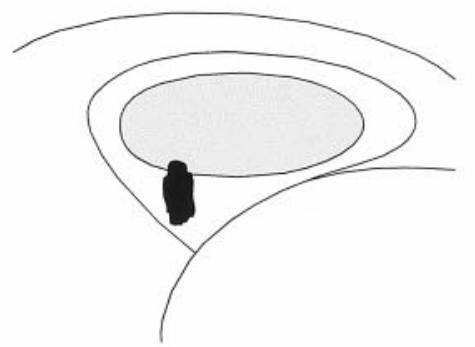

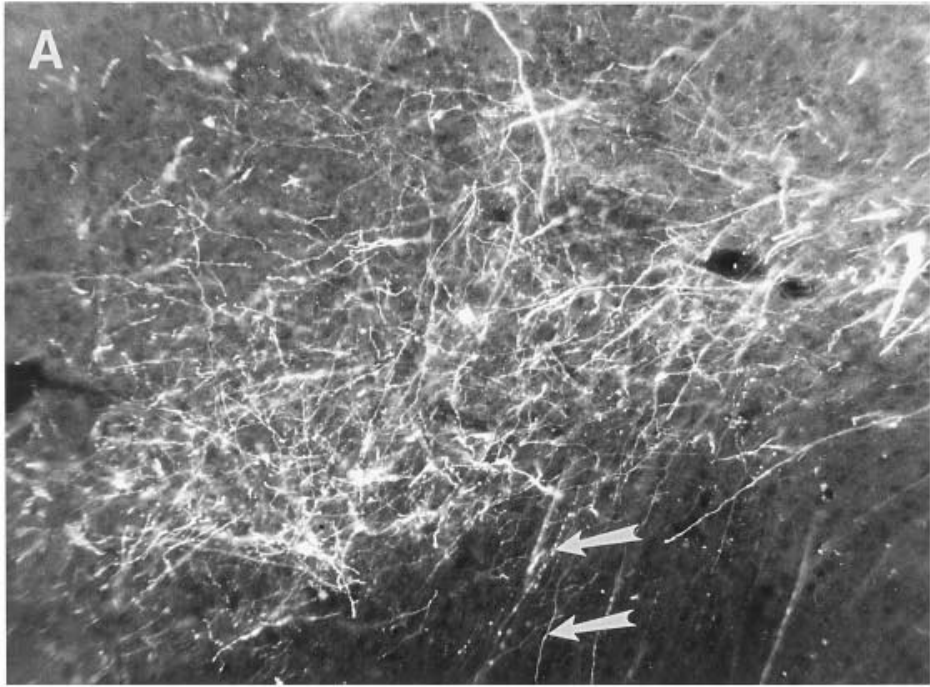
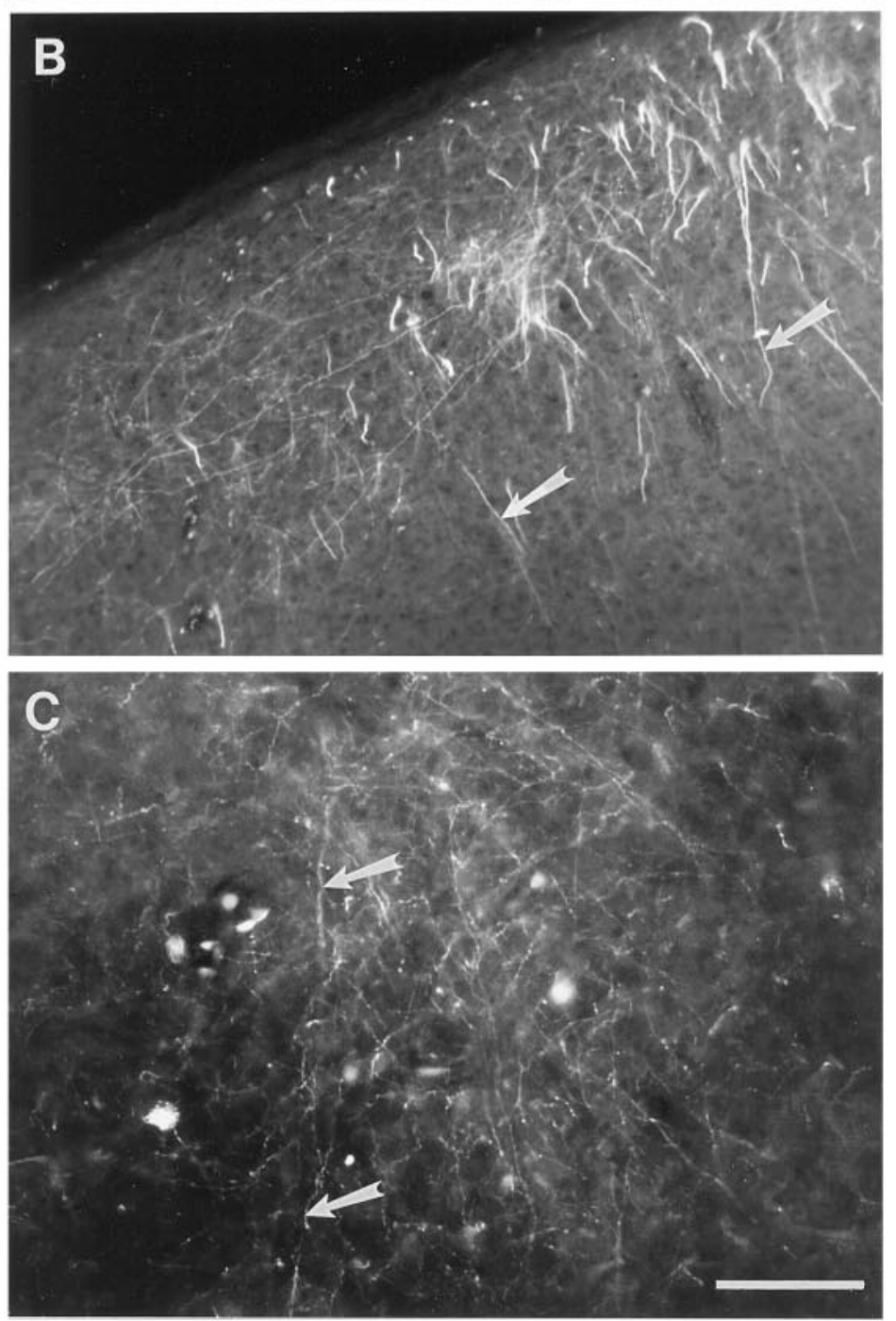

Figure 11. Photomicrographs showing anterograde label over dNCL after injections of RDA into $1 \mathrm{MAN}$ shell. $A$, An injection of RDA in the lateral part of $1 \mathrm{MAN}_{\text {shell }}$ in an adult bird produced terminal label in lateral dNCL. $B$, An injection of RDA into the ventromedial lMAN $\mathrm{N}_{\text {shell }}$ in a $35 \mathrm{~d}$ bird produced anterograde label over medial dNCL, whereas $C$, lateral dNCL, was labeled from an injection into ventrolateral $1 \mathrm{MAN}_{\text {shell }}$ in a $20 \mathrm{~d}$ bird. Injection sites are shown in schematics (on left). Inset above schematics of injections sites demonstrates anterograde label over lateral (black) and medial (gray) dNCL

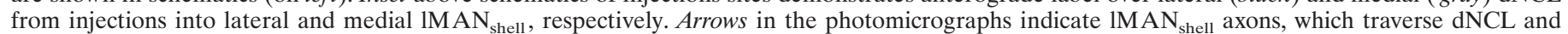
ultimately arborize within Ad. Scale bar, $200 \mu \mathrm{m}$. 
anterograde label within RA to vary as a function of dorsoventral position of the injection site. For example, all injections into lateral $1 \mathrm{MAN} \mathrm{N}_{\text {core }}$ of adult birds produce labeled axon terminals in medial and/or ventral portions of RA, regardless of their dorsoventral position.

A particularly striking example of the tendency of IMAN axons to ramify throughout RA of $20 \mathrm{~d}$ birds is shown in Figure $5 D$. An RDA injection into a ventral-intermediate subregion of $\mathrm{IMAN}_{\text {core }}$ in this bird produced intense terminal label throughout RA, excluding only a very small region along its ventrolateral border. A similar injection into intermediate $1 \mathrm{MAN}_{\text {core }}$ of an adult bird produced label restricted to the ventrolateral part of RA (data not shown). Thus, in contrast to the adult pattern, small regions of $1 \mathrm{MAN} \mathrm{N}_{\text {core }}$ project to relatively large target regions in RA, such that groups of neurons within adjacent subregions of $1 \mathrm{MAN} \mathrm{N}_{\text {core }}$ in $20 \mathrm{~d}$ birds have overlapping terminal fields that encompass a large proportion of RA. In fact, if comparable specificity of matching between afferent inputs and target regions was to be preserved at both ages, the terminal field of $1 \mathrm{MAN}$ core axons would have to be much smaller in absolute size in juveniles than in adults because the overall size of RA is much smaller in $20 \mathrm{~d}$ birds (see Discussion).

Additional examples demonstrate further that the tendency of $1 \mathrm{MAN} \mathrm{N}_{\text {core }}$ neurons to project to a relatively large region within $\mathrm{RA}$ in $20 \mathrm{~d}$ birds was not restricted to a particular subregion within $\mathrm{IMAN}_{\text {core }}$. An injection of RDA into the dorsomedial part of $1 \mathrm{MAN}_{\text {core }}$ that also extended slightly into ventromedial $1 \mathrm{MAN} \mathrm{N}_{\text {core }}$ in a $20 \mathrm{~d}$ bird labeled axonal arbors throughout dorsal and intermediate RA with the exception of a small region in dorsolateral RA that was very sparsely labeled (Fig. 6B). Large parts of ventrolateral and ventromedial RA were also anterogradely labeled by this injection. In an adult bird with a comparable, albeit slightly smaller injection into dorsomedial $1 \mathrm{MAN}_{\text {core }}$, anterograde label encompassed only dorsal RA (Fig. 6A). Thus, when injections were (roughly) matched for dorsoventral as well as mediolateral sites within $\mathrm{IMAN}_{\text {core }}$, anterograde label produced by these injections was restricted to a much smaller proportion of RA in adults as compared with $20 \mathrm{~d}$ birds.

Interestingly, the location of anterograde label produced by injections into different sites within $1 \mathrm{MAN}_{\text {core }}$ also suggested that the pattern of axonal connectivity from $1 \mathrm{MAN}_{\text {core }}$ to $\mathrm{RA}$ is different between $20 \mathrm{~d}$ and adult birds. That is, axon arbors of $1 \mathrm{MAN} \mathrm{N}_{\text {core }}$ neurons at $20 \mathrm{~d}$ were not preferentially localized to the subregions within RA that they will ultimately innervate in adulthood. For example, in Figure $5 C$, although anterograde label fills the ventral two-thirds of RA in a $20 \mathrm{~d}$ bird after an injection into the dorsal region of lateral and intermediate $1 \mathrm{MAN} \mathrm{N}_{\text {core, }}$, the terminal field within ventromedial RA is sparser than that within the ventrolateral part of RA. In an adult, an injection within the ventral region of lateral and intermediate $1 \mathrm{MAN}_{\text {core }}$ specifically labels the mediocentral part of RA, whereas the ventrolateral subregion of RA is devoid of label (Fig. $5 A$ ). Likewise, the injection site shown in Figure $5 D$ (into ventral-intermediate $1 \mathrm{MAN} \mathrm{N}_{\text {core }}$ ) would produce anterograde label in ventrolateral RA of an adult bird, but this region of RA is the most sparsely labeled in this $20 \mathrm{~d}$ bird. Overall, the results in $20 \mathrm{~d}$ birds indicate that the pattern of connectivity from $1 \mathrm{MAN}_{\text {core }}$ to $\mathrm{RA}$ is less refined as compared with adult birds.

$35 d$ birds. The topographic organization of the $\mathrm{MMAN}_{\text {core }} \rightarrow \mathrm{RA}$ circuit in $35 \mathrm{~d}$ birds was comparable to the restricted pattern of topography in this circuit present in adult birds as demonstrated by anterograde label over RA produced by eight of eight RDA injections in $1 \mathrm{MAN}_{\text {core }}$. Of these injections, four were in lateral, two were in medial, and two were in lateral-intermediate $\mathrm{lMAN}_{\text {core }}$. An RDA injection in the dorsolateral part of $1 \mathrm{MAN}_{\text {core }}$ in a $35 \mathrm{~d}$ bird produced a terminal field confined to ventromedial RA (Fig. 5B). Labeled axons could be seen traversing lateral and dorsal regions of RA in this bird but they arborized only within ventromedial RA. Interestingly, anterograde label in this $35 \mathrm{~d}$ bird appears to be even more restricted compared with that seen in the adult bird (Fig. $5 A$ ) that received an injection into ventrolateral and intermediate $1 \mathrm{MAN}_{\text {core }}$. Furthermore, the size and location of this injection site are well matched to that shown for a $20 \mathrm{~d}$ bird in Figure $5 C$, but the resultant patterns of anterograde label are dramatically different. That is, the proportion of RA encompassed by labeled axon terminals is much higher in the $20 \mathrm{~d}$ bird, and the location of the terminal field is not centered in ventral or medial regions of $\mathrm{RA}$, as would be expected for an injection site into lateral $1 \mathrm{MAN}_{\text {core }}$ in older birds. These findings indicate that patterns of topography within the $1 \mathrm{MAN}_{\text {core }} \rightarrow \mathrm{RA}$ circuit vary depending on the age of the bird: whereas small subgroups of $1 \mathrm{MAN} \mathrm{core}_{\text {co }}$ neurons have overlapping terminal fields within RA at $20 \mathrm{~d}$, these terminal fields are restricted within different subregions of RA by $35 \mathrm{~d}$. In addition, fluorescent tracer injections into different subregions of $1 \mathrm{MAN}_{\text {core }}$ of $35 \mathrm{~d}$ birds produced label specifically within corresponding regions of RA, which matched the pattern of topography seen in adults. Thus, the $1 \mathrm{MAN}_{\text {core }} \rightarrow \mathrm{RA}$ circuit becomes topographically refined to match the adult pattern between 20 and $35 \mathrm{~d}$ in male zebra finches, during early stages of song learning.

\section{Topographic organization of the $l M A N_{\text {core }} \rightarrow X$ circuit}

Adults. Neurons in $\mathrm{IMAN}_{\text {core }}$ also make a topographic projection to Area X, a nucleus within the avian basal ganglia (NixdorfBergweiler et al., 1995; Vates and Nottebohm, 1995). That is, neurons along the dorsal extent of $1 \mathrm{MAN}_{\text {core }}$ project to dorsal parts of Area $X$, whereas neurons in more ventral parts of $1 \mathrm{MAN}$ core project to the ventral part of Area $X$. In the present study, we found that 18 of 18 RDA injections into lateral $(n=8)$, intermediate $(n=4)$, or medial $(n=6)$ parts of $1 \mathrm{MAN}_{\text {core }}$ produced patches of anterograde label largely confined to corresponding lateral, intermediate, and medial subregions of Area X, confirming and extending the pattern of topographic connectivity in this pathway. Anterograde label over the dorsomedial part of Area X from an RDA injection into the dorsomedial region of $1 \mathrm{MAN}_{\text {core }}$ is shown in Figure $7 A$. Labeled axons from neurons in dorsomedial $1 \mathrm{MAN}$ core crossed the fiber tract lamina medullaris dorsalis (LMD) (Fig. 7A, arrowheads), which lies ventral to $1 \mathrm{MAN}_{\text {core }}$ and arborized within the dorsomedial part of Area X.

Juvenile birds (35 and $20 \mathrm{~d}$ ). Eight of eight injections of RDA into different subregions of $1 \mathrm{MAN}_{\text {core }}$ in $35 \mathrm{~d}$ (six in lateral and two in medial core) and 20 of 20 injections in $20 \mathrm{~d}$ birds (seven in lateral, four in intermediate, and nine in medial core) produced anterograde label mainly within lateral, intermediate, and medial regions of Area X, showing that the $\mathrm{IMAN}_{\text {core }} \rightarrow$ Area $X$ pathway displays coarse topographic organization throughout song learning. An injection into intermediate $1 \mathrm{MAN}_{\text {core }}$ of a $20 \mathrm{~d}$ bird produced anterograde label largely confined to the intermediate part of Area X (Fig. 7B). As in adults, axons from neurons within intermediate $\mathrm{IMAN}_{\text {core }}$ in this bird did not arborize extensively within either lateral or medial subregions of Area X or in any part of LPO. This result is somewhat surprising in view of the fact that individual $1 \mathrm{MAN}_{\text {core }}$ neurons send axon collaterals to both RA and Area X (Nixdorf-Bergweiler et al., 1995; Vates and Notte- 
bohm, 1995). Therefore, the present results indicate that axon collaterals to RA are not specifically restricted to their ultimate target fields, whereas axon collaterals to $\mathrm{X}$ appear to be topographically restricted at $20 \mathrm{~d}$ (despite the smaller size of Area X in $20 \mathrm{~d}$ birds compared with adults). It should be noted that the same injections in $20 \mathrm{~d}$ birds that did not give evidence of developmental differences in axon targeting from $\mathrm{IMAN}_{\text {core }} \rightarrow$ Area X or from $\mathrm{DLM}_{\mathrm{DL}} \rightarrow \mathrm{IMAN}_{\text {core }}$ did show differences in topographic specificity from $\mathrm{IMAN}_{\text {core }} \rightarrow \mathrm{RA}$. That is, identical injections (i.e., within the same bird) produce the same topographic pattern of retrograde label in $\mathrm{DLM}_{\mathrm{DL}}$ and of anterograde label in Area X between $20 \mathrm{~d}$ and adulthood, but nevertheless produce a less refined pattern of anterograde label in RA at $20 \mathrm{~d}$ than in adulthood. This pattern also underscores our conclusion that the relative lack of topographic specificity in the $\mathrm{IMAN}_{\text {core }} \rightarrow \mathrm{RA}$ projection of $20 \mathrm{~d}$ birds does not reflect specific injection sites.

\section{Topographic organization of the $I M A N_{\text {shell }} \rightarrow$ Ad circuit}

Adult birds. Seventeen of 17 injections of RDA into lateral $(n=$ $10)$ or medial $(n=7) 1 \mathrm{MAN}_{\text {shell }}$ produced anterograde label over lateral or medial subregions of ipsilateral Ad, respectively. Figure $8 \mathrm{~A}$ shows anterograde label within the lateral part of Ad resulting from an injection of RDA into lateral $1 \mathrm{MAN}_{\text {shell }}$ of an adult bird. Some of the labeled axons crossed the dorsolateral border of Ad and entered lateral Ad directly whereas others entered dorsal intermediate Ad and then turned laterally before arborizing specifically within lateral Ad. Thus, the topographic projections between $1 \mathrm{MAN}_{\text {shell }} \rightarrow \mathrm{Ad}$ in adult males seen in this study were comparable to those described by Johnson et al. (1995) (compare Fig. 10B).

Juvenile birds (35 and 20 d). Injections of RDA into $1 \mathrm{MAN}_{\text {shell }}$ of $35 \mathrm{~d}$ (seven of seven injections analyzed; four in lateral and three in medial shell) and $20 \mathrm{~d}$ birds (17 of 17 injections; 10 in lateral, seven in medial shell) produced patterns of anterograde label similar to those seen in normal adults. That is, fluorescent tracer injections into lateral and medial $1 \mathrm{MAN}_{\text {shell }}$ produced anterograde label over corresponding lateral and medial parts of Ad, which matched the patterns of connectivity in the $\mathrm{IMAN}_{\text {shell }} \rightarrow$ Ad circuit of adult male birds. RDA injections into lateral $1 \mathrm{MAN} \mathrm{N}_{\text {shell }}$ in a 35 and a $20 \mathrm{~d}$ bird produced labeled axons that crossed the dorsal border of Ad and arborized within its lateral subregion (Fig. $8 B, C$, respectively), which was comparable to the organization of the lateral $1 \mathrm{MAN}_{\text {shell }} \rightarrow$ lateral Ad present in adult birds (Fig. 8A).

\section{Topographic organization of the $l M A N_{\text {shell }} \rightarrow L P O$ circuit}

Adult birds. Ten of 10 injections that were restricted to lateral $1 \mathrm{MAN} \mathrm{N}_{\text {shell }}$ and seven of seven injections in medial $1 \mathrm{MAN}_{\text {shell }}$ also gave rise to anterogradely labeled axons that crossed LMD and arborized within corresponding lateral and medial regions of LPO (LPO is the medial striatal region of the avian basal ganglia which includes Area X, shown diagrammatically in Fig. 10A). Some of the RDA-labeled axons from neurons in $1 \mathrm{MAN}$ shell traversed Area X after crossing LMD but all of them arborized solely within specific regions of LPO. Anterograde label within LPO produced by injections into $1 \mathrm{MAN}_{\text {shell }}$ was never as intense as that in Area X produced by injections into $\mathrm{lMAN}_{\text {core }}$, suggesting that the projection from $1 \mathrm{MAN}_{\text {core }}$ to Area $\mathrm{X}$ may be more robust than the $1 \mathrm{MAN}_{\text {shell }} \rightarrow \mathrm{LPO}$ circuit. Figure $9 A$ demonstrates anterograde label over the lateral part of LPO after an injection of RDA into lateral $1 \mathrm{MAN}_{\text {shell }}$ of an adult bird. These topograph- ically organized $1 \mathrm{MAN}_{\text {shell }} \rightarrow \mathrm{LPO}$ circuits in male zebra finches have not been described previously.

Juvenile birds (35 and 20 d). The $1 \mathrm{MAN}_{\text {shell }} \rightarrow$ LPO projection was also present in 35 and $20 \mathrm{~d}$ birds and was topographically organized. Injections of RDA into the lateral region of $1 \mathrm{MAN}_{\text {shell }}$ in a $35 \mathrm{~d}$ and in a $20 \mathrm{~d}$ bird anterogradely labeled axons that crossed LMD and produced terminal fields in lateral LPO (lateral to Area X; Fig. 9B,C) that were comparable to that present in an adult bird with a similar injection in lateral $1 \mathrm{MAN}_{\text {shell }}$ (Fig. $9 A$ ). Similarly, RDA injections into medial $1 \mathrm{MAN}_{\text {shell }}$ in juvenile birds of both ages produced anterograde label over medial LPO (data not shown). Seven of seven injections in $35 \mathrm{~d}$ birds of which four were in lateral and three in medial $1 \mathrm{MAN}_{\text {shell }}$ and 17 of 17 injections in $1 \mathrm{MAN}_{\text {shell }}$ of $20 \mathrm{~d}$ birds (10 in lateral and seven in medial shell) demonstrated these patterns of topography.

\section{Topographic organization of the $l M A N_{\text {shell }} \rightarrow d N C L$ circuit}

Adult birds. In addition to anterograde label over LPO and Ad, 17 of 17 injections of RDA into $\mathrm{IMAN}_{\text {shell }}$ also produced a large terminal field in dNCL, a cortical region situated caudolateral to $\mathrm{HVC}$ at the level of RA and Ad. This projection from $1 \mathrm{MAN}_{\text {shell }}$ to dNCL has also not been described previously (Figs. 10B, 11 $A$ ). Although some $1 \mathrm{MAN}_{\text {shell }}$ axons that terminate in Ad pass medially to the dNCL terminal field, many axons from $1 \mathrm{MAN}_{\text {shell }}$ neurons traverse this terminal field en route to $\mathrm{Ad}$, as depicted in Figures $10 B$ and $11 A$ (arrows). The $\mathrm{lMAN}_{\text {shell }} \rightarrow \mathrm{dNCL}$ circuit also showed broad patterns of topography, as 10 of 10 RDA injections into lateral $1 \mathrm{MAN}_{\text {shell }}$ produced label over more lateral parts of dNCL, whereas seven of seven injections into medial $\mathrm{IMAN}_{\text {shell }}$ produced anterograde label over medial dNCL. The existence of this pathway has been confirmed by J. D. Brady, B. E. Cribbs, and S. W. Bottjer (unpublished data), who made injections of RDA into dNCL and observed retrogradely labeled neurons in $1 \mathrm{MAN}_{\text {shell }}$. Thus, in addition to the projection from $1 \mathrm{MAN} \mathrm{N}_{\text {shell }}$ to $\mathrm{Ad}$, the present results reveal that $1 \mathrm{MAN}_{\text {shell }}$ has two novel efferent targets, LPO and dNCL, and both $\mathrm{IMAN}_{\text {shell }} \rightarrow$ LPO and $\mathrm{IMAN}_{\text {shell }} \rightarrow \mathrm{dNCL}$ circuits are topographically organized.

Juvenile birds (35 and 20 d). The $1 \mathrm{MAN}_{\text {shell }} \rightarrow \mathrm{dNCL}$ projection was also present in juvenile zebra finches and was comparable to the pathway seen in adult males. Seven of seven injections into $1 \mathrm{MAN}_{\text {shell }}$ in $35 \mathrm{~d}$ birds (four in lateral and three in medial shell) and 17 of 17 injections into $1 \mathrm{MAN}_{\text {shell }}$ in $20 \mathrm{~d}$ birds (10 in lateral and seven in medial shell) confirmed these results. Figure $11 C$ shows a terminal field of label in dNCL produced by an injection into ventrolateral $1 \mathrm{MAN} \mathrm{N}_{\text {shell }}$ in a $20 \mathrm{~d}$ bird. Labeled axons from ventrolateral $1 \mathrm{MAN}_{\text {shell }}$ in $20 \mathrm{~d}$ birds (arrows) traversed dNCL before arborizing in $\mathrm{Ad}$, a pattern of organization similar to that seen in adults. In a $35 \mathrm{~d}$ bird, an injection of RDA into ventromedial $1 \mathrm{MAN}_{\text {shell }}$ produced a terminal field in the medial region of dNCL (Fig. 11B). Labeled axons from ventromedial $1 \mathrm{MAN}_{\text {shell }}$ neurons, which terminated in medial Ad, traversed this terminal field in dNCL before descending toward Ad. These findings indicate that broad patterns of axonal connectivity between $1 \mathrm{MAN} \mathrm{N}_{\text {shell }}$ and Ad, LPO, and dNCL in $20 \mathrm{~d}, 35 \mathrm{~d}$, and adult birds are comparable. Therefore, the $1 \mathrm{MAN}_{\text {shell }} \rightarrow \mathrm{Ad}$, $\mathrm{lMAN}_{\text {shell }} \rightarrow \mathrm{LPO}$, and $\mathrm{IMAN}_{\text {shell }} \rightarrow \mathrm{dNCL}$ projections are already established at the onset of song learning and are topographically organized in a manner similar to that seen in adults. 


\section{Quantitative analysis of the IMAN core $\rightarrow$ RA circuit}

As described above, anterograde label produced by small injections of RDA into $1 \mathrm{MAN}_{\text {core }}$ in $20 \mathrm{~d}$ birds encompassed a considerably greater proportion of RA than did comparable injections in $35 \mathrm{~d}$ or adult birds. This finding indicates that groups of neurons within $1 \mathrm{MAN}$ core tend to have overlapping terminal fields in $20 \mathrm{~d}$ birds but not in $35 \mathrm{~d}$ or adult birds. To confirm that the results we observed were not merely a reflection of the volume or location of the injection within $1 \mathrm{MAN}_{\text {core }}$, we quantified the difference in the $1 \mathrm{MAN}_{\text {core }} \rightarrow \mathrm{RA}$ circuit in $20 \mathrm{~d}, 35 \mathrm{~d}$, and adult birds only from well defined $1 \mathrm{MAN}_{\text {core }}$ injection sites as well as the terminal fields in RA that these injections produced (see Materials and Methods). The results, shown in Table 2, reinforce our conclusion that comparable dye injections into $1 \mathrm{MAN}_{\text {core }}$ of $20 \mathrm{~d}$ birds produce label over a much greater proportion of RA compared with $35 \mathrm{~d}$ and adult birds. These changes in the $\mathrm{IMAN}_{\text {core }} \rightarrow \mathrm{RA}$ circuit are even more striking given the fact that dye injections of similar size across different ages should, if anything, label fewer $1 \mathrm{MAN}_{\text {core }}$ projection neurons in $20 \mathrm{~d}$ versus adult birds (Nordeen et al., 1992; Nixdorf-Bergweiler et al., 1995) (also see Materials and Methods, section on Analysis). For example, comparably sized injections of RDA were made in the medial part of $1 \mathrm{MAN}_{\text {core }}$ in a $20 \mathrm{~d}$ bird (Pu511) and an adult bird (Bk311). Although the resultant volume of anterograde label within RA was smaller in the $20 \mathrm{~d}$ bird than in the adult, the proportion of RA occupied by anterograde label was substantially higher in the $20 \mathrm{~d}$ bird (98\%) as compared with the adult (39\%). A similar comparison can also be made for Pu514 lt (a $20 \mathrm{~d}$ bird) and the adult bird W421 with injections in medial-intermediate $1 \mathrm{MAN} \mathrm{N}_{\text {core }}$. Despite comparably sized injections that produced (in these cases) similar volumes of anterograde label in RA, the proportion of RA covered by labeled axons was considerably higher in the $20 \mathrm{~d}$ bird $(72 \%)$ than in the adult bird (36\%). These findings indicate that the proportion of RA occupied by the labeled $1 \mathrm{MAN}_{\text {core }}$ terminal field is substantially higher in $20 \mathrm{~d}$ than in adult birds and that these differences do not reflect variations in injection volume or injection site within $1 \mathrm{MAN}_{\text {core }}$.

Across all injections, the percentage of RA volume occupied by labeled $1 \mathrm{MAN}_{\text {core }}$ axons was substantially larger in $20 \mathrm{~d}$ birds $(65 \%)$ compared with adult birds $(37 \%)$ and $35 \mathrm{~d}$ birds $(22 \%)$ $\left(F_{(2,24)}=23.8 ; p<0.0001\right)$. Planned comparisons showed that the proportion of RA occupied by anterogradely labeled axon arbors was higher in $20 \mathrm{~d}$ birds than in either $35 \mathrm{~d}$ or adult birds (both $p<0.05)$. Although the proportion of RA occupied by labeled axons was lowest in $35 \mathrm{~d}$ birds, this value was not significantly lower when compared with adults $(p>0.05)$.

The volume of RA increases greatly over the course of song learning, caused primarily by an increase in spacing between a stable number of neurons $\left(F_{(2,24)}=27.7 ; p<0.0001\right.$, see Table 2) (cf. Konishi and Akutagawa, 1985; Bottjer et al., 1986; Herrmann and Bischof, 1986; Nordeen and Nordeen, 1988a,b). Although the proportion of RA covered by the $1 \mathrm{MAN}_{\text {core }}$ terminal field was substantially larger in $20 \mathrm{~d}$ birds versus adults and $35 \mathrm{~d}$ birds, the total volume of the $1 \mathrm{MAN}_{\text {core }}$ terminal field was smaller in juvenile birds than in adults (overall $F_{(2,24)}=3.72 ; p=0.04$ ). Table 2 shows that the size of the terminal field in RA across all injection sites was $\sim 30 \%$ larger in adults than in $20 \mathrm{~d}$ birds (0.108 vs 0.082 $\left.\mathrm{mm}^{3}\right)$, although this difference was not statistically significant $(p>0.05)$. The size of the terminal field was smallest in $35 \mathrm{~d}$ birds $\left(0.059 \mathrm{~mm}^{3}\right)$, and this value was significantly less than that observed in adults $(p<0.05)$ but not in $20 \mathrm{~d}$ birds $(p>0.05)$.
Because of the substantial growth in the overall volume of RA between 20 and $35 \mathrm{~d}$, the targeting of labeled axon terminals to restricted subregions of RA was therefore greatest in $35 \mathrm{~d}$ birds (i.e., a smaller terminal field was localized within an expanding postsynaptic target). Because the total number of $1 \mathrm{MAN}_{\text {core }}$ projection neurons remains constant throughout song learning (Nordeen et al., 1992), any change in the $\mathrm{IMAN}_{\text {core }}$ terminal field would have to occur at the level of individual axon arbors of $1 \mathrm{MAN} \mathrm{N}_{\text {core }}$ neurons in RA. Our results indicate that the absolute volume of the $1 \mathrm{MAN}$ core terminal field is small at $20 \mathrm{~d}$ and decreases somewhat by $35 \mathrm{~d}$ as RA grows, suggesting that individual $1 \mathrm{MAN}$ core terminals in RA may undergo remodeling and regression between 20 and $35 \mathrm{~d}$, resulting in a refinement of the axonal connection between these two nuclei. The $1 \mathrm{MAN}_{\text {core }}$ terminal field then expands to match its expanding target after $35 \mathrm{~d}$ to achieve its adult configuration.

\section{Quantitative analysis of the IMAN $\mathbf{N}_{\text {core }} \rightarrow X$ circuit}

In contrast to the $1 \mathrm{MAN}_{\text {core }} \rightarrow \mathrm{RA}$ circuit, which is poorly refined at the onset of song learning (20 d), overall patterns of connectivity from $1 \mathrm{MAN}_{\text {core }}$ neurons to Area $\mathrm{X}$ at $20 \mathrm{~d}$ were similar to those seen at $35 \mathrm{~d}$ and adulthood. The proportion of Area X volume occupied by the $1 \mathrm{MAN}$ core terminal field was only slightly higher in $20 \mathrm{~d}$ birds $(20 \%)$ compared with adult birds $(16 \%)$ across all injection sites within $1 \mathrm{MAN}_{\text {core }}$, and this difference was not significant $(F<1$; see Table 3$)$. Comparing anterograde label produced by RDA injections of similar size and location within $\mathrm{IMAN}_{\text {core }}$ in $20 \mathrm{~d}$ and adult birds revealed a similar trend. For example, injections of comparable volume were made into the medial part of $1 \mathrm{MAN}_{\text {core }}$ in a $20 \mathrm{~d}$ bird (Pu511) and an adult (Bk311). Although the overall volume of the terminal field was smaller in the $20 \mathrm{~d}$ bird than in the adult, the proportion of Area $\mathrm{X}$ volume occupied by anterograde label from $1 \mathrm{MAN} \mathrm{core}_{\text {co }}(31 \%)$ was slightly higher than that in the adult (24\%). However, inspection of Table 3 shows that the percentage of Area X occupied by the $1 \mathrm{MAN}$ core terminal field was highly variable within both $20 \mathrm{~d}$ and adult birds, such that the range of overlap between the two groups was considerable. The absence of a significant difference between the percentage of Area X occupied by $1 M A N_{\text {core }}$ terminals at $20 \mathrm{~d}$ compared with adult birds substantiates our qualitative observations of the similarity between broad patterns of topographic organization within the $\mathrm{MAN}_{\text {core }} \rightarrow$ Area $\mathrm{X}$ circuit throughout song learning.

The overall volume of Area X expands greatly between $20 \mathrm{~d}$ and adulthood $\left(F_{(1,16)}=63.0 ; p<0.0001\right.$, Table 3 ) (cf. Bottjer et al., 1985; Nordeen and Nordeen, 1988a,b). Our results therefore suggest that axon arbors of $1 \mathrm{MAN}_{\text {core }}$ neurons projecting to Area $\mathrm{X}$ are extensively remodeled throughout song learning to maintain a correct "topographic alignment" within their expanding target, because the broad pattern of topographic organization of this circuit is comparable in $20 \mathrm{~d}$ and adult birds (a situation reminiscent of the retinotectal projection in frogs) (Reh and Constantine-Paton, 1984; Cline and Constantine-Paton, 1990). Whereas the percentage of Area $\mathrm{X}$ occupied by the $1 \mathrm{MAN} \mathrm{N}_{\text {core }}$ terminal field is roughly comparable at $20 \mathrm{~d}$ and adulthood, the absolute volume of anterograde label within Area $\mathrm{X}$ tends to be smaller in $20 \mathrm{~d}$ birds, although this difference was not significant $\left(F_{(1,16)}=1.16 ; p=0.30\right)$. This pattern also suggests that modifications within individual $1 \mathrm{MAN}_{\text {core }}$ axon arbors act to maintain topographic connections within Area X throughout song learning. Specifically, the dramatic growth in the overall size of Area X suggests that individual $1 \mathrm{MAN}_{\text {core }}$ arbors may grow to match 
their postsynaptic target. Thus, topographic projections between $1 \mathrm{MAN} \mathrm{N}_{\text {core }}$ and its targets RA and Area X must both be remodeled during song learning, albeit to different degrees and perhaps by different mechanisms.

\section{DISCUSSION}

Our results show that axonal connections to and from IMAN are present in juvenile male zebra finches at the onset of song learning $(20 \mathrm{~d})$ and are, in most instances, topographically similar to their counterparts in adult birds that have completed the acquisition of stable song patterns. The present experiments provide ample evidence of the similarity of broad patterns of topography within most song-control circuits in juvenile and adult birds, although they obviously do not preclude fine-grained rearrangements (e.g., at the level of individual arbors; cf. Iyengar and Bottjer, 1998). Nevertheless, it is striking that broad patterns of axonal connectivity between subsets of neurons are so similar throughout the period for vocal learning, during which time experience is of paramount importance in acquiring and refining vocal patterns and song-control circuits are undergoing gross morphological changes (Johnson and Bottjer, 1992). These results indicate that the initial development of coarse topographic organization in song-control circuits of zebra finches is independent of experiences associated with vocal learning, suggesting that the basic scaffolding of song-control circuitry may be specified innately and serve as a necessary prerequisite for vocal learning (Burek et al., 1991; Bottjer, 1997; Bottjer and Arnold, 1997; Iyengar et al., 1997; cf. Seidenberg, 1997). This pattern underscores the inherent ability of the nervous system to establish highly organized patterns of connectivity (Goodman and Shatz, 1993; Tessier-Lavigne and Goodman, 1996; Feldman and Knudsen, 1997). The fine details of these highly organized patterns of innate connections are modified and/or maintained by experiential factors in many neural systems (Wallhaüser-Franke et al., 1995; Crair et al., 1998).

Behavioral evidence has suggested that innately specified circuits form templates that contain pre-encoded information about conspecific song (Marler, 1997; Whaling et al., 1997; cf. Bottjer, 1997). These innate templates may serve to guide the generation of incipient vocalizations while juvenile birds refine their song patterns during sensorimotor integration. Song production in juvenile birds that have been deafened or placed in social isolation without access to a tutor's song is abnormal, but retains some species-specific characteristics (Konishi, 1965; Immelman, 1969; Marler and Sherman, 1983; Eales, 1985, 1987). Perhaps the songs of acoustically isolated birds are guided by circuitry that contains information concerning some basic characteristics of conspecific song. Our results, indicating that broad patterns of axonal connectivity to and from $1 \mathrm{MAN}$ are established early in development, suggest that these pathways may be candidates for such innately specified circuits.

\section{Broad topographic patterns within the IMAN core $_{\rightarrow}$ RA circuit are refined during the early stages of song learning}

A striking exception to the adult-like pattern of organization seen in most circuits during early stages of song learning was provided by the $\mathrm{IMAN}_{\text {core }} \rightarrow \mathrm{RA}$ projection. In adult and $35 \mathrm{~d}$ birds, small groups of neurons within specific subregions of $1 \mathrm{MAN}$ core project to restricted groups of postsynaptic target cells in RA. In $20 \mathrm{~d}$ birds, neurons within specific subregions of $1 \mathrm{MAN}_{\text {core }}$ project to a much larger proportion of RA, and broad patterns of connec- tivity within the $1 \mathrm{MAN}$ core $\rightarrow \mathrm{RA}$ circuit tend to differ from the adult pattern. Thus, overall topography within the $\mathrm{IMAN}_{\text {core }} \rightarrow \mathrm{RA}$ circuit is poorly refined at $20 \mathrm{~d}$, and neurons within different subregions of $1 \mathrm{MAN}_{\text {core }}$ have overlapping terminal fields within RA at this age. RA contains a myotopic map of the syrinx (Vicario, 1991; Wild, 1993a, 1997), and this map may be preserved upstream in the DLM $\mathrm{DL}_{\mathrm{DL}} \rightarrow \mathrm{IMAN}_{\text {core }} \rightarrow \mathrm{RA}$ circuit (Johnson et al., 1995; Vates and Nottebohm, 1995). The refinement in topographic connectivity of the $\mathrm{lMAN}_{\text {core }} \rightarrow \mathrm{RA}$ circuit during early stages of song development therefore suggests an increase in refinement of vocal motor control that may be reflected in song behavior. During early stages of song learning, juvenile swamp sparrows sing a large number of notes (subsong) of which only a small number are retained in the adult song, and the morphology of individual notes becomes increasingly stereotyped (Marler and Peters, 1982). Our findings are therefore consistent with the idea that the emergence of coarse topography within the $1 \mathrm{MAN}_{\text {core }} \rightarrow \mathrm{RA}$ circuit at 35 d signifies a behavioral transition, perhaps reflecting in part the initial transition from subsong to plastic song and pruning of the vocal repertoire (cf. Marler, 1991; Margoliash, 1997; Nordeen and Nordeen, 1997).

What mechanisms underlie these developmental changes in the $\mathrm{IMAN}_{\text {core }} \rightarrow \mathrm{RA}$ circuit? The number of neurons in male RA is thought to be fixed by $\sim 20 \mathrm{~d}$, although the overall size of RA increases greatly during vocal development: the density of neurons in RA is high at $20 \mathrm{~d}$, but thereafter the size and spacing of RA neurons increases over the course of song learning, leading to a substantial increase in RA volume during this period (Konishi and Akutagawa, 1985; Bottjer et al., 1986; Herrmann and Bischof, 1986; Nordeen and Nordeen, 1988a; Kirn and DeVoogd, 1989). The smaller size of RA in $20 \mathrm{~d}$ birds has interesting implications for patterns of topographic specificity, in that small groups of IMAN neurons would have to project to even more restricted areas of RA than at older ages to preserve similar patterns of axonal connectivity. The present results show that this is clearly not the case. Although the absolute volume occupied by labeled axons from $1 \mathrm{MAN}_{\text {core }}$ is much smaller in $20 \mathrm{~d}$ than in adult birds (Table 2), the proportion of RA occupied by this terminal field is nevertheless the largest at $20 \mathrm{~d}$ because of the much smaller size of RA at this age. Because the number of $\mathrm{IMAN}_{\text {core }}$ projection neurons remains constant throughout song learning (Nordeen et al., 1992), the developmental changes that we observed in their terminal field within RA presumably occur at the level of individual $1 \mathrm{MAN}_{\text {core }}$ axon arbors. Thus, our results suggest that axon terminals of single $1 \mathrm{MAN} \mathrm{N}_{\text {core }}$ neurons overlap to a greater extent at $20 \mathrm{~d}$ than at $35 \mathrm{~d}$ or adulthood.

In contrast to the relative lack of specificity in the $1 \mathrm{MAN}_{\text {core }} \rightarrow \mathrm{RA}$ projection at $20 \mathrm{~d}$, the restriction of $1 \mathrm{MAN}$ axons to specific regions within RA may be greatest in $35 \mathrm{~d}$ birds, as evidenced by the slight decrease in the size of the $1 \mathrm{MAN}$ core terminal field within an expanding RA at this age. Interestingly, $35 \mathrm{~d}$ birds appear to be at the height of the sensitive period for learning notes from a tutor song model (Immelmann, 1969; Böhner, 1990; Zann, 1990; Slater et al., 1993). Thus, whatever information is being mapped within the $\mathrm{IMAN}_{\text {core }} \rightarrow \mathrm{RA}$ circuit, the degree of refinement or the grain of this map may be the best around the time when birds are acquiring a memory of song sounds. After $35 \mathrm{~d}$, continued remodeling of axon terminals may give rise to the adult pattern of connectivity within the $\mathrm{IMAN}_{\text {core }} \rightarrow \mathrm{RA}$ circuit. The idea that $\mathrm{IMAN}_{\text {core }} \rightarrow \mathrm{RA}$ axon terminals undergo axonal remodeling and synaptic rearrangements during the period of song learning is supported by the 
finding that the number of synapses made by $1 \mathrm{MAN}_{\text {core }}$ axons onto RA neurons decreases substantially over the course of vocal development (Herrmann and Arnold, 1991). Interestingly, although axon remodeling also plays a role in the refinement of circuits in other neural systems, such remodeling is usually accompanied by an increase in synapse number (Purves and Lichtman, 1985; O'Leary et al., 1986; O'Rourke and Fraser, 1986; Sretavan and Shatz, 1986; Cline and Constantine-Paton, 1990; Campbell and Shatz, 1992; Simon and O'Leary, 1992; Antonini and Stryker, 1993; Roskies et al., 1995; Krug et al., 1998).

\section{Broad topographic patterns within the IMAN circuit are adult-like at the onset of vocal learning}

Individual RA-projecting neurons within $\mathrm{IMAN}_{\text {core }}$ also send an axon collateral to Area $\mathrm{X}$ in adult male zebra finches (NixdorfBergweiler et al., 1995; Vates and Nottebohm, 1995). We found that axon arbors of $1 \mathrm{MAN}_{\text {core }}$ neurons formed topographically restricted projections within Area $\mathrm{X}$ at $20 \mathrm{~d}$, comparable to those in adults. This is a striking finding, considering that axon collaterals of the same neurons that arborize within the "correct" topographic region of Area X at $20 \mathrm{~d}$ fail to innervate a restricted subset of RA neurons with any great precision. This finding suggests that postsynaptic target factors may contribute to differences in establishment of overall topography within $1 \mathrm{MAN}$ core $\rightarrow$ Area $\mathrm{X}$ and $1 \mathrm{MAN}_{\text {core }} \rightarrow \mathrm{RA}$ circuits during song learning. It should be stressed however, that although coarse topography is present throughout song learning in the $\mathrm{IMAN}_{\text {core }} \rightarrow$ Area $\mathrm{X}$ projection, this circuit must be actively remodeled during this time to preserve overall topography in the face of dramatic growth of Area X.

The finding that axon collaterals of $1 \mathrm{MAN}_{\text {core }}$ neurons maintain a more restricted pattern of arborization within Area $X$ than in $\mathrm{RA}$ of $20 \mathrm{~d}$ birds raises the question of whether this difference has a functional correlate in song behavior. Interestingly, inputs to RA from HVC change substantially during song learning, whereas HVC inputs to Area X appear to be conserved. Newly generated HVC neurons send axons down to RA in both developing zebra finches and adult canaries as new song patterns are learned, whereas the projection of a separate population of HVC neurons to Area $\mathrm{X}$ is stable (i.e., these neurons are born in ovo and are not replaced by new neurons) (Alvarez-Buylla et al., 1988; Nordeen and Nordeen, 1988b). This pattern provides an interesting correlate to the results of the present study and may reflect the fact that RA is directly on-line for vocal production, and hence remodeling of inputs to RA (from both 1 MAN and HVC) may be necessary to encode a specific vocal pattern. In contrast, Area X may be involved in basic aspects of vocal learning (Sohrabji et al., 1990; Scharff and Nottebohm, 1991; Jarvis et al., 1998), but is presumably not part of the direct motor pathway for song production. Thus, stability of topographic inputs to Area $\mathrm{X}$ from IMAN may be required in order for this circuit to serve some learning function (as opposed to encoding the program for execution of the learned behavior).

\section{Loops within song control circuits: analogies to mammalian basal ganglia}

Patterns of topography within the $\mathrm{DLM}_{\mathrm{DL}} \rightarrow \mathrm{IMAN}_{\text {core }}$ and $\mathrm{DLM}_{\mathrm{VM}} \rightarrow \mathrm{IMAN}_{\text {shell }}$ circuits at $20 \mathrm{~d}$ were comparable to those in adult birds. The efferent projections of $1 \mathrm{MAN}_{\text {shell }}$ were also topographically organized throughout vocal learning. We found that $1 \mathrm{MAN}$ shell neurons project not only to Ad, but also to LPO and dNCL, newly described projections that parallel the

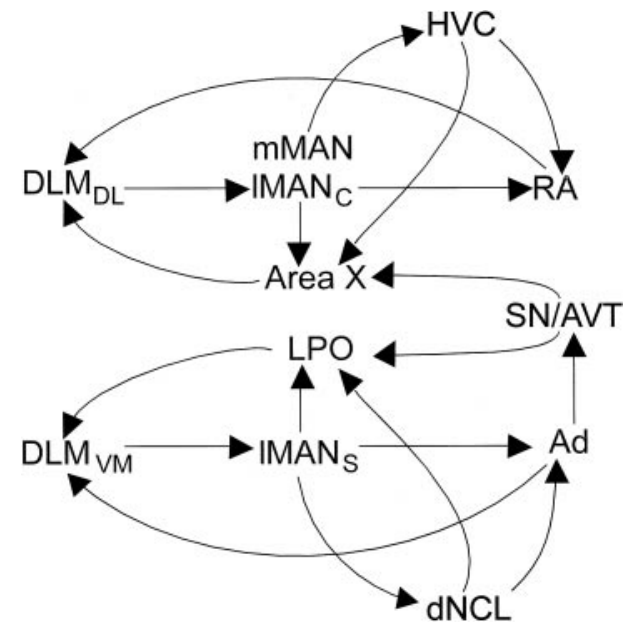

Figure 12. Schematic of the major connections of core and shell, showing a remarkable degree of similarity in the overall patterns of connectivity within the projections to and from $1 \mathrm{MAN}_{\text {core }}$ and $1 \mathrm{MAN}_{\text {shell }}$. In addition to the $\mathrm{DLM}_{\mathrm{DL}} \rightarrow \mathrm{IMAN}_{\text {core }} \rightarrow \mathrm{RA}$ and $\mathrm{DLM}_{\mathrm{VM}} \rightarrow \mathrm{MAN}_{\text {shell }} \rightarrow$ Ad projections, which parallel each other (Johnson et al., 1995), the $\mathrm{IMAN}_{\text {core }} \rightarrow$ Area X circuit (Vates and Nottebohm, 1995) mirrors the $\mathrm{IMAN}_{\text {shell }} \rightarrow$ LPO circuit (present study). Both Area X and LPO project to the thalamic nucleus DLM (Bottjer et al., 1989; S. Iyengar and S. W. Bottjer, unpublished observations), forming loops that may provide feedback about song to the rest of the song control circuitry. The RA/ Ad $\rightarrow$ DLM $\rightarrow$ IMAN loops (Wild, 1993b; Brady, Cribbs, and Bottjer, unpublished observations) may be important for integrating descending motor output $(R A)$ and diverse kinds of sensory information $(A d$, see below) with song learning. Both Area X and RA of the core pathway receive afferent input from the higher vocal center (HVC) (Nottebohm et al., 1976), which is paralleled by analogous projections from dNCL onto LPO and Ad within the shell pathway (Brady, Cribbs, and Bottjer, unpublished observations). Additionally, the mMAN $\rightarrow \mathrm{HVC}$ circuit within the core projection (Nottebohm et al., 1982; Foster et al., 1997; Foster and Bottjer, 1998) is mirrored by the $\mathrm{IMAN}_{\text {shell }} \rightarrow \mathrm{dNCL}$ circuit (present study) within the shell pathway. Interestingly, the Ad $\rightarrow \mathrm{SN} / \mathrm{AVT}$ circuit (Brady, Cribbs, and Bottjer, unpublished observations), which provides dopaminergic input to Area X and LPO (Lewis et al., 1981), may influence both core and shell pathways. Links between these two pathways are also provided by the $\mathrm{RA} / \mathrm{Ad} \rightarrow \mathrm{DLM} / \mathrm{DMP} \rightarrow \mathrm{MMAN} / \mathrm{mMAN}$ projections (Foster et al., 1997) (data not shown), through efferent targets of mMAN, that is, HVC and Area X. LPO, Parolfactory lobe, the medial component of the avian striatum; $H V C$, higher vocal center; $m M A N$, medial magnocellular nucleus of the anterior neostriatum; $d N C L$, caudolateral neostriatum; $D M P$, dorsomedial nucleus of the posterior thalamus.

$1 \mathrm{MAN}_{\text {core }} \rightarrow$ Area $\mathrm{X}$ circuit and $\mathrm{mMAN} \rightarrow \mathrm{HVC}$ circuits, respectively (Nottebohm et al., 1982; Foster et al., 1997; Foster and Bottjer, 1998) (Fig. 12). The presence of the $\mathrm{IMAN}_{\text {shell }} \rightarrow \mathrm{LPO}$ circuit has been confirmed by Brady, Cribbs, and Bottjer (unpublished observations), who found that small injections of dye into Ad backfill a spatially restricted subset of neurons within IMANshell, which in turn send axon collaterals into restricted regions of LPO. Thus, the same subset of $1 \mathrm{MAN}_{\text {shell }}$ neurons that project to Ad also project to LPO and provide pathways that are parallel to the $\mathrm{IMAN}_{\text {core }} \rightarrow \mathrm{RA}$ /Area $\mathrm{X}$ connections.

Figure 12 demonstrates the "litany of loops" within the song control system referred to by Bottjer and Johnson (1997), with some additions based on recent findings. Interestingly, accruing evidence supports the existence of two major subdivisions of IMAN circuitry into distinct core and shell pathways, suggesting that each may process different types of information or subserve different functions for vocal learning. The majority of projections to and from the core and shell regions of IMAN appear to be 
mirror images of one another, suggesting some potential similarities in how information is processed by these two pathways. Each of these pathways is characterized by multiple feedback loops and multiple points of potential contact where information may be integrated both within and between pathways. The core pathway is apt to be directly involved with motor aspects of song behavior, because the output of RA neurons goes directly to vocal motor neurons. Interestingly, there is a dramatic increase in the overall volume of $1 \mathrm{MAN}_{\text {shell }}$ (Johnson and Bottjer, 1992) accompanied by an increase in the refinement of individual $\mathrm{DLM}_{\mathrm{VM}}$ axon arbors within this region between 20 and 35 d (Iyengar and Bottjer, 1998). The time course of this growth and regression seems to parallel the functional involvement of IMAN in vocal learning and suggests that $1 \mathrm{MAN}_{\text {shell }}$ may be actively involved in some aspect of vocal learning at the height of the sensitive period for song acquisition (Weinberger, 1995; cf. Bottjer, 1997). However, the $1 \mathrm{MAN}_{\text {shell }} \rightarrow$ Ad pathway is unlikely to play any direct role in vocal production because the output of Ad does not go to vocal motor neurons (Brady, Cribbs, and Bottjer, unpublished observations). Both RA and Ad send projections to a dorsal thalamic zone (including both DLM and DMP), thereby creating potential feedback loops that may be involved in integrating descending motor output and other kinds of sensory information with song learning.

The large number of loops within song-control circuitry suggests a high degree of feedback and integration at different levels within these circuits (cf. Johnson and Bottjer, 1997). The overall $\mathrm{X} \rightarrow \mathrm{DLM} \rightarrow \mathrm{IMAN}$ circuitry (both core and shell) is a basal ganglia $\rightarrow$ thalamus $\rightarrow$ cortex pathway and appears to provide a classic example of parallel pathways characterized by both convergence $(X \rightarrow D L M)$ and divergence (DLM $\rightarrow$ IMAN), suggesting strong similarities to the organization of mammalian basal ganglia circuitry. This type of organization may provide a neural strategy for expanding the amount of brain space devoted to processing and analyzing multiple features of song-related information (cf. Graybiel et al., 1994). Both Area X and LPO are components of the avian basal ganglia (striatum) (Reiner et al., 1984) and receive dopaminergic inputs from the substantia nigra (SN) and ventral tegmental area (AVT) (Lewis et al., 1981; Bottjer, 1993). Whereas the function of LPO in song learning has not been examined, lesions of Area $\mathrm{X}$ in juvenile zebra finches disrupt vocal production (Sohrabji et al., 1990; Scharff and Nottebohm, 1991). Whereas lesions of Area X in adult birds do not disrupt song production, the act of singing induces strong induction of the immediate early gene $Z E N K$ in a context-dependent manner: $Z E N K$ is induced only when birds are singing in isolation (practicing?), but not when they are courting a female (Jarvis et al., 1998). Thus, the $\mathrm{X} \rightarrow \mathrm{DLM} \rightarrow \mathrm{IMAN}$ pathway may be similar to mammalian basal ganglia pathways in terms of an involvement in motor aspects of learning, planning, and coordination of movement and motivation (Alexander et al., 1986; Alexander, 1994; Graybiel et al., 1994, 1995a,b; Mink, 1996; cf. Bottjer and Johnson, 1997).

\section{REFERENCES}

Agmon A, Yang LT, O'Dowd DK, Jones EG (1993) Organized growth of thalamocortical axons from the deep tier of terminations into layer IV of developing mouse barrel cortex. J Neurosci 13:5365-5382.

Agmon A, Yang LT, Jones EG, O’Dowd DK (1995) Topological precision in the thalamic projection to neonatal mouse barrel cortex. J Neurosci 15:549-561.

Alexander GE (1994) Basal ganglia-thalamocortical circuits: their role in control of movements. J Clin Neurophysiol 11:420-431.
Alexander GE, DeLong MR, Strick PL (1986) Parallel organization of functionally segregated circuits linking basal ganglia and cortex. Annu Rev Neurosci 9:357-381.

Antonini A, Stryker MP (1993) Development of individual geniculocortical arbors in cat striate cortex and effects of binocular impulse blockade. J Neurosci 13:3549-3573.

Alvarez-Buylla A, Theelen M, Nottebohm F (1988) Birth of projection neurons in the higher vocal center of the canary forebrain before, during, and after song learning. Proc Natl Acad Sci USA 85:8722-8726.

Böhner J (1990) Early acquisition of song in the zebra finch. Anim Behav 39:369-374.

Bottjer SW (1993) The distribution of tyrosine hydroxylase immunoreactivity in the brains of male and female zebra finches. J Neurobiol 24:51-69.

Bottjer SW (1997) Building a bird brain: sculpting neural circuits for a learned behavior. Bioessays 19:1109-1116.

Bottjer SW, Arnold AP (1997) Developmental plasticity in neural circuits for a learned behavior. Annu Rev Neurosci 20:459-481.

Bottjer SW, Johnson F (1997) Circuits, hormones, and learning: vocal behavior in songbirds. J Neurobiol 33:602-618.

Bottjer SW, Sengelaub DR (1989) Cell death during development of a forebrain nucleus involved with vocal learning in zebra finches. J Neurobiol 20:609-618.

Bottjer SW, Miesner EA, Arnold AP (1984) Forebrain lesions disrupt development but not maintenance of song in passerine birds. Science 224:901-903.

Bottjer SW, Glaessner SL, Arnold AP (1985) Ontogeny of brain nuclei controlling song learning and behavior in zebra finches. J Neurosci 5:1556-1562.

Bottjer SW, Miesner EA, Arnold AP (1986) Changes in neuronal number, density and size account for increases in volume of song-control nuclei during song development in zebra finches. Neurosci Lett 67:263-268.

Bottjer SW, Halsema KA, Brown SA, Miesner EA (1989) Axonal connections of a forebrain nucleus involved with song learning in zebra finches. J Comp Neurol 279:312-326.

Burek MJ, Nordeen KW, Nordeen EJ (1991) Neuron loss and addition in developing zebra finch song nuclei are independent of auditory experience during song learning. J Neurobiol 22:215-223.

Campbell G, Shatz CJ (1992) Synapses formed by identified retinogeniculate axons during the segregation of eye input. J Neurosci 12:1847-1858.

Catalano SM, Robertson RT, Killackey HP (1991) Early ingrowth of thalamocortical afferents to the neocortex of the prenatal rat. Proc Natl Acad Sci USA 88:2999-3003.

Cline HT, Constantine-Paton M (1990) NMDA receptor agonist and antagonists alter retinal ganglion cell arbor structure in the developing frog retinotectal projection. J Neurosci 10:1197-1216.

Crair MC, Gillespie DC, Stryker MP (1998) The role of visual experience in the development of columns in cat visual cortex. Science 279:566-570.

Eales LA (1985) Song learning in zebra finches: some effects of song model availability on what is learnt and when. Anim Behavior 33:1293-1300.

Eales LA (1987) Song learning in female-raised zebra finches: another look at the sensitive phase. Anim Behav 35:1356-1365.

Feldman DE, Knudsen EI (1997) An anatomical basis for visual calibration of the auditory space map in the barn owl's midbrain. J Neurosci 17:6820-6837.

Foster EF, Bottjer SW (1998) Axonal connections of the high vocal center and surrounding cortical regions in juvenile and adult male zebra finches. J Comp Neurol 397:118-138.

Foster EF, Mehta RP, Bottjer SW (1997) Axonal connections of the medial magnocellular nucleus of the anterior neostriatum in zebra finches. J Comp Neurol 382:364-381.

Goodman C, Shatz CJ (1993) Developmental mechanisms that generate precise patterns of neuronal connectivity. Cell 10[Suppl]:77-98.

Graybiel AM (1995a) The basal ganglia. Trends Neurosci 18:60-62.

Graybiel AM (1995b) Building action repertoires: memory and learning functions of the basal ganglia. Curr Opin Neurobiol 5:733-741.

Graybiel AM, Aosaki T, Flaherty AW, Kimura M (1994) The basal ganglia and adaptive motor control. Science 265:1826-1831.

Herrmann K, Arnold AP (1991) The development of afferent projections to the robust archistriatal in male zebra finches: a quantitative electron microscopic study. J Neurosci 11:2063-2074. 
Herrmann K, Bischof HJ (1986) Delayed development of song control nuclei in the zebra finch is related to behavioral development. J Comp Neurol 245:167-175.

Immelman K (1969) Song development in the zebra finch and other estrildid finches. In: Bird vocalizations (Hinde RA, ed), pp 61-77. Cambridge: Cambridge UP.

Iyengar S, Bottjer SW (1998) Growth and regression in a thalamocortical projection during the sensitive period for vocal learning in zebra finches. Soc Neurosci Abstr 24:1189.

Iyengar S, Viswanathan SS, Bottjer SW (1997) Development of topographic organization in neural circuits for vocal learning in zebra finches. Soc Neurosci Abstr 23:1330.

Jarvis ED, Scharff C, Grossman MR, Ramos JA, Nottebohm F (1998) For whom the bird sings: context-dependent gene expression. Neuron 21:775-788.

Johnson F, Bottjer SW (1992) Growth and regression of thalamic efferents in the song-control system of male zebra finches. J Comp Neurol 326:442-450.

Johnson F, Sablan MM, Bottjer SW (1995) Topographic organization of a forebrain pathway involved with vocal learning in zebra finches. J Comp Neurol 358:260-278.

Kirn JR, DeVoogd TJ (1989) Genesis and death of vocal control neurons during sexual differentiation in the zebra finch. J Neurosci 9:3176-3187.

Konishi M (1965) The role of auditory feedback in the control of vocalization in the white-crowned sparrow. Z Tierpsychol 22:770-783.

Konishi M, Akutagawa E (1985) Neuronal growth, atrophy and death in a sexually dimorphic song nucleus in the zebra finch brain. Nature 315:145-147.

Krug K, Smith AL, Thompson ID (1998) The development of topography in the hamster geniculo-cortical projection. J Neurosci 18:5766-5776.

Lewis JW, Ryan SM, Arnold AP, Butcher LL (1981) Evidence for a catecholaminergic projection to Area $\mathrm{X}$ in the zebra finch. J Comp Neurol 196:347-354.

Margoliash D (1997) Functional organization of forebrain pathways for song production and perception J Neurobiol 33:671-693.

Marler P (1991) Song-learning behavior: the interface with neuroethology. Trends Neurosci 14:199-206.

Marler P (1997) Three models of song learning: evidence from behavior. J Neurobiol 33:501-516.

Marler P, Peters S (1982) Developmental overproduction and selective attrition: new processes in the epigenesis of birdsong. Dev Psychobiol 15:369-378.

Marler P, Sherman V (1983) Song structure without auditory feedback: emendations of the auditory template hypothesis. J Neurosci 3:517-531.

Mink JW (1996) The basal ganglia: focused selection and inhibition of competing motor programs. Prog Neurobiol 50:381-425.

Nixdorf-Bergweiler BE, Lips MB, Heinemann U (1995) Electrophysiological and morphological evidence for a new projection of LMANneurones toward Area X. NeuroReport 6:1729-1732.

Nordeen EJ, Nordeen KW (1988a) Sex and regional differences in the incorporation of neurons born during song learning in zebra finches. J Neurosci 8:2869-2874.

Nordeen KW, Nordeen EJ (1988b) Projection neurons within a vocal motor pathway are born during song learning in zebra finches. Nature 334:149-151.

Nordeen KW, Nordeen EJ (1997) Anatomical and synaptic substrates for avian song learning. J Neurobiol 33:532-548.

Nordeen EJ, Grace A, Burek MJ, Nordeen KW (1992) Sex-dependent loss of projection neurons involved in avian song learning. J Neurobiol 23:671-679.
Nottebohm F, Kelley DB, Paton JA (1982) Connections of vocal control nuclei in the canary telencephalon. J Comp Neurol 207:344-357.

O'Leary DD, Fawcett JW, Cowan WM (1986) Topographic targeting errors in the retinocollicular projection and their elimination by selective ganglion cell death. J Neurosci 6:3692-3705.

O'Rourke NA, Fraser SE (1986) Dynamic aspects of retinotectal map formation revealed by a vital-dye fiber-tracing technique. Dev Biol 114:265-276.

Purves D, Lichtman JW (1985) Rearrangement of developing neuronal connections. In: Principles of neural development, pp 271-300. Sunderland, MA: Sinauer.

Reh TA, Constantine-Paton M (1984) Retinal ganglion cell terminals change their projection sites during larval development of Rana pipiens. J Neurosci 4:442-457.

Reiner A, Davis BM, Brecha NC, Karten HJ (1984) The distribution of enkephalinlike immunoreactivity in the telencephalon of the adult and developing domestic chicken. J Comp Neurol 228:245-262.

Roskies A, Friedman GC, O'Leary DD (1995) Mechanisms and molecules controlling the development of retinal maps. Perspect Dev Neurobiol 3:63-75.

Scharff C, Nottebohm F (1991) A comparative study of the behavioral deficits following lesions of various parts of the zebra finch song system: implications for vocal learning. J Neurosci 11:2896-2913.

Seidenberg MS (1997) Language acquisition and use: learning and applying probabilistic constraints. Science 275:1599-1603.

Simon DK, O'Leary DD (1992) Development of topographic order in the mammalian retinocollicular projection. J Neurosci 12:1212-1232.

Slater PJB, Jones AE, ten Cate CJ (1993) Can lack of experience delay the end of the sensitive phase for song learning? Netherlands J Zool 40:80-90.

Sohrabji F, Nordeen EJ, Nordeen KW (1990) Selective impairment of song learning following lesions of a forebrain nucleus in the juvenile zebra finch. Behav Neural Biol 53:51-63.

Sretavan DW, Shatz CJ (1986) Prenatal development of retinal ganglion cell axons: segregation into eye-specific layers within the cat's lateral geniculate nucleus. J Neurosci 6:234-251.

Tessier-Lavigne M, Goodman CS (1996) The molecular biology of axon guidance. Science 274:1123-1133.

Vates GE, Nottebohm F (1995) Feedback circuitry within a songlearning pathway. Proc Natl Acad Sci USA 92:5139-5143.

Vicario DS (1991) Organization of the zebra finch song control system: II. Functional organization of outputs from nucleus Robustus archistriatalis. J Comp Neurol 309:486-494.

Wallhaüsser-Franke E, Nixdorf-Bergweiler BE, DeVoogd TJ (1995) Song isolation is associated with maintaining high spine frequencies on zebra finch IMAN neurons. Neurobiol Learn Mem 64:25-35.

Weinberger NM (1995) Dynamic regulation of receptive fields and maps in the adult sensory cortex. Annu Rev Neurosci 18:129-158.

Wild JM (1993a) The avian nucleus retroambigualis: a nucleus for breathing, singing and calling. Brain Res 606:319-324.

Wild JM (1993b) Descending projections of the songbird nucleus robustus archistriatalis. J Comp Neurol 338:225-241.

Wild JM (1997) Neural pathways for the control of birdsong production. J Neurobiol 33:653-670.

Whaling CS, Solis MM, Doupe AJ, Soha JA, Marler P (1997) Acoustic and neural bases for innate recognition of song. Proc Natl Acad Sci USA 94:12694-12698.

Zann R (1990) Song and call learning in wild zebra finches in south-east Australia. Anim Behav 40:811-828.

Zann RA (1996) Vocalizations. In: The zebra finch. A synthesis of field and laboratory studies (CM Perrins, ed), pp 196-247. New York: Oxford UP. 